Portland State University

PDXScholar

1989

\title{
Goals of international exchange : an exploratory study of why American host families participate in international exchange programs
}

Deborah Lee Fisher-Moore

Portland State University

Follow this and additional works at: https://pdxscholar.library.pdx.edu/open_access_etds

Part of the International and Area Studies Commons, and the International and Intercultural

Communication Commons

Let us know how access to this document benefits you.

\section{Recommended Citation}

Fisher-Moore, Deborah Lee, "Goals of international exchange : an exploratory study of why American host families participate in international exchange programs" (1989). Dissertations and Theses. Paper 3569. https://doi.org/10.15760/etd.5453

This Thesis is brought to you for free and open access. It has been accepted for inclusion in Dissertations and Theses by an authorized administrator of PDXScholar. Please contact us if we can make this document more accessible: pdxscholar@pdx.edu. 
AN ABSTRACT OF THE THESIS OF Deborah Lee Fisher-Moore for the Master of Arts in speech Communication presented February $23,1989$.

Title: Goals of International Exchange: An Exploratory study of why American Host Families Participate in International Exchange Programs

APPROVED BY MEMBERS QF THE THESIS COMMITTEE:

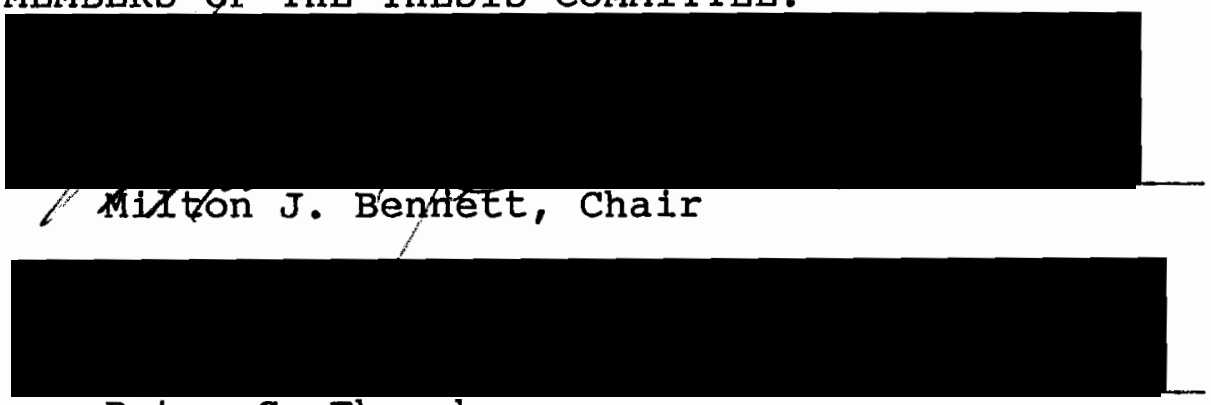

Peter C. Ehrenhaus

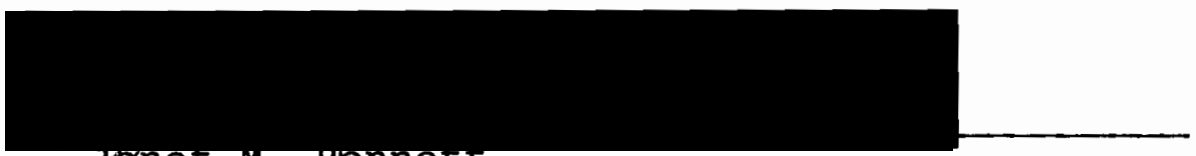

yanet M. Bennet

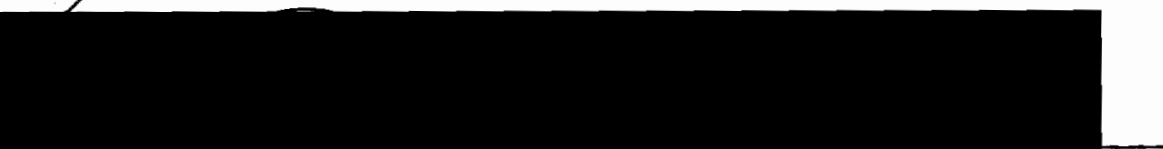

Victor C. Dahl

This thesis presents the findings of a descriptive study of goals of international exchange and how they are perceived in terms of relevance by host family participants in homestay exchange programs.

The literature of international exchange was examined to identify goals as established and defined by researchers 
in the field. Experienced exchange coordinators, host families and others were interviewed for their suggestions of additional goals not discussed in the literature. A survey questionnaire was developed and administered to 69 host family members from Tillamook County, oregon. They were asked to evaluate the importance and achievement of 14 literature-based and 22 non-literature-based goals represented by 43 two-part questions.

The quantitative and qualitative aspects of the results were evaluated. The data showed that the host families perceived only five literature-based and two non-literature-based goals as important. Understanding another culture was ranked first among the literature-based goals, which is congruent with results from other studies that evaluated the objectives of international exchange sponsors and study abroad students.

These results indicate that host family expectations are limited compared to goals expressed in the literature. To enhance their cross-cultural experience, suggestions were made for developing training programs that address host family needs while helping participants become more aware of all the goals of international exchange. The value of this study is that it provides a cohesive list of goals and a survey instrument that can be used both for training purposes and for an overall evaluation of the host family component in international exchange programs. 
GOALS OF INTERNATIONAL EXCHANGE:

AN EXPLORATORY STUDY OF WHY AMERICAN HOST FAMILIES PARTICIPATE IN INTERNATIONAL EXCHANGE PROGRAMS

\author{
by \\ DEBORAH L. FISHER-MOORE
}

A thesis submitted in partial fulfillment of the requirements for the degree of

\author{
MASTER OF ARTS \\ in \\ SPEECH \\ COMMUNICATION
}

Portland State University

1989 
TO THE OFFICE OF GRADUATE STUDIES:

The members of the Committee approve the thesis of Deborah Lee Fisher-Moore presented February 23, 1989.

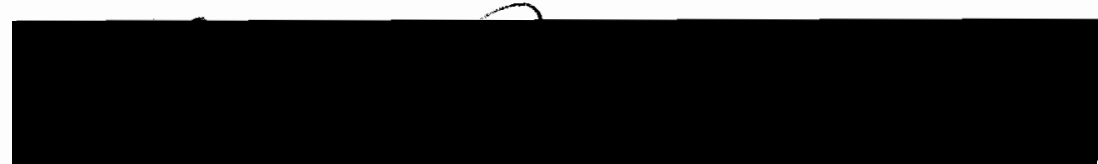

MIlton J.'Benirett, Chair

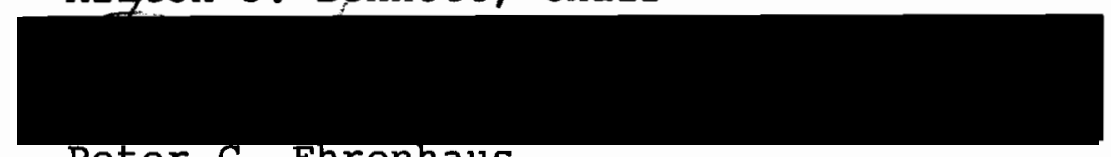

Peter C. Ehrenhaus

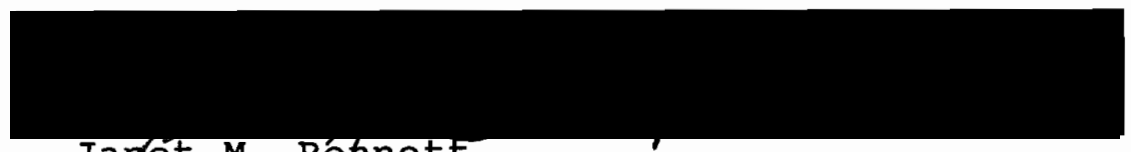

Jaget M. Béhnett

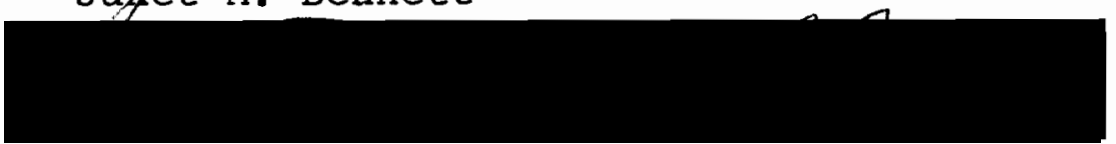

Victor C. Dahl

APPROVED :

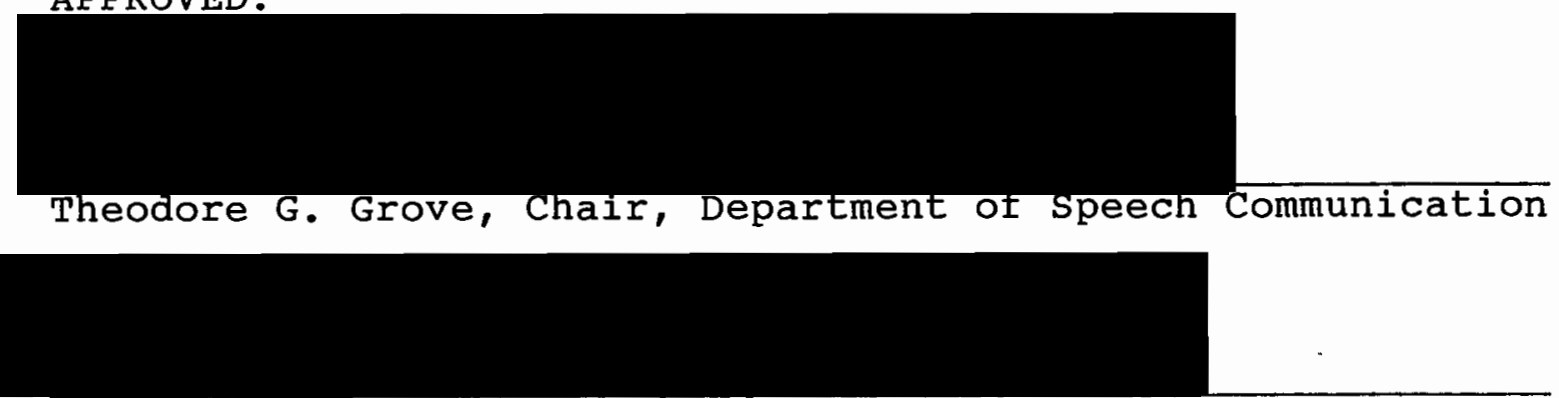

Bernard Ross, Vice Provost for Graduate Studies 


\section{ACKNOWLEDGEMENTS}

Many people have given generously of their time, knowledge and patience toward the completion of this thesis.

I wish to thank Dr. Milton J. Bennett and Dr. Peter C. Ehrenhaus for their invaluable guidance and constant encouragement. For the help he gave me with the statistical aspects of this study, I would like to thank Dr. Theodore C. Grove. And I would especially like to thank Mrs. LaRay Barna for introducing me to the field of intercultural communication.

To my friends, Marge and Ben Bernhard and Debby Halliburton, I would like to express my appreciation for their support and hospitality through the years I commuted to school. I am indebted to my father, Raymond H. Fisher, who inspired me with his own scholarly achievements and had enough faith in me to invest in my future. I would also like to thank my son, Joaquin, for understanding his mother so well, always prodding me to finish what I had begun.

I extend my love and appreciation to my best friend and husband, Larry, whose confidence in me is unending. For his patience and vision, I say thank-you.

Finally, I extend my thanks to the host families of Tillamook County, Oregon. Without their cooperation, this project could not have been done. 
TABLE OF CONTENTS

PAGE

ACKNOWLEDGEMENTS . . . . . . . . . . . . . . . iii LIST OF TABLES . . . . . . . . . . . . . . vi vi

CHAPTER

I

INTRODUCTION

Background To The Study . . . . . 3

Rationale For The Study . . . . . 6

Purpose of The Study . . . . . . 8

Organization of The Study . . . . 10

II REVIEW OF THE LITERATURE • • • • • • • • • 12

Literature Review Summary . . • . 30

III METHODOLOGY - • • • • • • • • • • • 32

Design of The study . • . . . . 32

Instrumentation . . . . . . . 33

Selection of The Sample Population . - 47

Preliminary And Actual study

Procedures . . . . . . . . . 51

Data Analysis Procedures . . . . . 54

IV RESULTS AND DISCUSSION • • • • • • • • 56

Host Family Demographics . . . . . 56

Host Family Ratings of Goals

For Importance... . . . . . . 59

Host Family Ratings of Goals

For Achievement . . . . . . . 84

Summary of Results . . . . . . . 88 
V IMPLICATIONS, APPLICATION AND LIMITATIONS OF THE STUDY . . . . . . . . . . . . . 96

Implications and Application . . . 96

Limitations of The Study With

Suggestions For Future Research . . 99

Conclusion . . . . . . . . 101

REFERENCES . . . . . . . . . . . . . 103

APPENDIX A ................... 110

APPENDIX B . . . . . . . . . . . . . . . 114

APPENDIX C . . . . . . . . . . . . . . . 133 


\section{LIST OF TABLES}

TABLE

PAGE

I

Mean Ratings For Importance of Literature-

Based Questionnaire Items By Host Families .

II Rank Order For Importance of Literature-

Based Questionnaire Items By Host Families .

II Order of Importance of Five NICSA Goals As

Rated By Students, NICSA Council And Tillamook

County Host Families . . . . . . . . . .

IV Mean Ratings For Importance of Non-LiteratureBased Goals By Host Families . . . . . . 81

V Rank Order For Importance of Non-LiteratureBased Goals By Host Families . . . . . . . 83

VI Rank Order of Literature-Based Goals Rated

$\geq 5.00$ For Achievement by Host Families . • 85

VII Rank order of Non-Literature-Based Goals Rated $\geq 5.00$ For Achievement by Host Families . . 85

VIII Summary of Goals Rated Important By Host Families . . . . . . . . . . . . . 89

IX Summary of Literature-Based Goals Rated Unimportant By Host Families . . . . . . . 92

$\mathrm{x}$ Mean Ratings For Importance And Achievement Of Literature-Based Goals . . . . . . . . 134 
vii

XI Mean Ratings For Importance And Achievement

Of Non-Literature-Based-Goals . . . . . 136 


\section{CHAPTER I}

\section{INTRODUCTION}

In the last forty-five years, millions of Americans have sojourned in other parts of the world for extended stays, and almost as many individuals from numerous other countries have come to the United States. They all are participants in a vast international exchange movement that has become a worldwide phenomenon. Traditionally, these sojourners have been young high school and college students pursuing academic studies abroad. More recently, special focus programs also have been developed which allow visiting teachers, workers and businesspeople to meet with their counterparts, to acquire special knowledge and skills and to enlarge their world view. Programs also exist for individuals who simply want to experience another culture in greater depth than would be possible when traveling as a tourist. For the most part, however, the typical exchange pattern is that of a foreign teen-ager living with a local family, learning the native culture and imparting knowledge about his or her own country.

International exchange is defined as cross-cultural contact involving face-to-face interaction between persons of two different countries, with emphasis upon the "differ- 
ent nationals as private individuals, although in a certain sense they may see themselves and be seen by others as representatives of their nations" (Kelman 1965, 30). Within the last century a few innovative thinkers and organizations have sought to enhance this cross-cultural experience by increasing the personal and individual dimension of the face-to-face interaction. Their approach has been to develop homestay programs in which visitors take up full-time residence in the home of a local host family.

For the visitor, this has involved complete immersion in the host culture in the sense that he or she is considered by the host family members to be an actively functioning member of their family (Grove 1988, 3). The homestay visitor is distinguished as someone different from a boarder, houseguest, visiting neighborhood friend, or live-in-help. He or she

learns about [local] family life from an insider's point of view...but remains essentially an outsider to long-standing family ties, the family's shared history, and the special sense of loyalty felt exclusively by family members (King \& Huff 1985, 8).

Although the visitor remains an outsider, he or she participates in the family's normal day-to-day activities. Through discussions, the [visitor] usually develops a strong friendship with family members, a relationship of deep caring and high mutual regard (ibid., 9).

So that cultural immersion becomes complete, the visitor sometimes is encouraged to have little or no interaction with others who come from his or her home country. The 
experience should continue for a significant duration of time, from three weeks to as long as a year (Grove 1988; Lowe, et al., 49).

Host families, who have been described as "that absolutely critical element in the exchange endeavor" (King \& Huff, 122), consist of local nationals who, within a nuclear family context, provide room and board and interpersonal communication in a cross-cultural context (ibid. $x x$ ). Typically, they represent a cross-section of occupations, income levels and ethnic groups. They encompass a broad age range, and there may or may not be natural children living at home. They are located in "medium-sized cities, affluent suburbs, small towns, and isolated rural areas" (Grove 1984, 3).

\section{BACKGROUND TO THE STUDY}

In the United States, the original live-with-a-family program was initiated by The Experiment in International Living in 1932. It was designed as a short-term summer exchange whose primary focus was the experience of living as a member of a host family in the United States. By the late 1950s, The Experiment had developed an international network that "was similar to the United Nations, with autonomous national offices in nearly 40 countries and Experimenters crossing international boundaries in all directions" (Batchelder 1977, 1). 
Others, who had experienced both World Wars, saw in international exchange an opportunity to express their commitment to international understanding and universal peace. AFS International/Intercultural Programs, one of the largest and most successful of organizations that promote intercultural learning, is an example. Their exchange programs originated with American Field Service volunteer ambulance drivers who had served in both wars. Deeply affected by the destruction and suffering they had witnessed, they established an international exchange program as their peacetime contribution to humanity.

Technological advancements developed during World War II made possible increased international contact and communication. People from diverse cultures had fought, worked and interacted together on a level greater than at any previous time in history. But more contact did not necessarily create more understanding. The idea that the world was shrinking, that we were becoming a "global village," and that nations, both weak and strong, were interdependent, now took on new significance. With the arrival of the Nuclear Age, and the accompanying threat of nuclear war, the very survival of humanity had come into question.

International exchange programs, which rest on the concept of universal peace (Carroll 1974, 31), assumed a new importance and their number increased dramatically by the 
$1950 \mathrm{~s}$. These programs were, and continue to be, viewed as a vehicle for positive change because most of the participants are young. With their youthful idealism and open-mindedness, it was thought that teen-agers would be the most receptive to the changes and new ideas that result from cultural exchange. Out of this generation, it was hoped, would emerge future world leaders whose task it would be to deal with the on-going issues of increased cross-cultural contact, interdependence of nations and a "shrinking" world.

It is in this context that international exchange programs have grown in popularity since the 1950s. Living with a host family as part of the exchange experience has also increased in popularity. Hundreds of programs exist, sponsored by both private sector organizations and national governments, offering families the opportunity to take part in this unique and rewarding experience. "Wanted: Host Families!" advertisements appear in newspapers. Printed handouts are distributed to American high school students, encouraging them and their families to have an "'international adventure' that will be remembered for years to come." Affirming the importance of international exchange, in 1982 President Reagan established the President's International Youth Exchange Initiative (E/YX) as a branch of the United States Information Agency. By 1985, an estimated 22,000 exchanges had been funded by E/YX grants, many of which included a homestay component. This 
interest demonstrates how host families have come to play a significant role in the growth and success of exchange programs.

\section{RATIONALE FOR THE STUDY}

Such growth, however, has not been without its problems. Programs have been developed in relative isolation from others and have lacked a well-defined theoretical framework which would allow for the systematic establishment of enrollment procedures and a clear delineation of goals and evaluation standards. Many programs lack adequate orientation and training components to help maximize the potential for intercultural learning that can be derived from the participants' experiences. Because of the spoken and unspoken assumption that such programs are inherently good and that contact between members of different cultures will result in positive attitudes towards each other, little attention has been paid to preparing participants for any possible negative aspects that might develop during an overseas sojourn (Bennett 1985, 3). Host families frequently receive little more than superficial training, which often consists of experienced host families telling anecdotes and providing "how to" information about the expected guest's food tastes, bathroom habits and the like. Considering the thousands of individuals involved in exchange every year, both as guests 
and as hosts, it is remarkable how casually it has been treated.

A substantial amount of research has been devoted to understanding the process of international exchange, with interest accelerating over the past two decades. But a review of the published literature reveals an imbalance of focus. Most studies have focused primarily on the adjustment and attitudes of foreign students visiting the United States and, to a lesser degree, on the experience of American students abroad (Sell 1983). Very little effort has been directed towards understanding the host community's experience. In effect, as Paige (1983) says,

[t]he almost exclusive concern with the effects of the dominant culture upon the sojourner has led most theoreticians and researchers to ignore the reverse side of the intercultural contact equation: the influence of the sojourner upon the host culture $(102)$.

Bochner (1982) suggests that to ignore the experience of the host community is to ignore the basic dynamic and processual nature of communication. As he states:

Individuals do not passively respond to their environments, but react and if possible modify their surroundings. Thus, when we speak of migrants adapting to their circumstances, we should ask to what extent, if any, has the host community changed as a consequence of an influx of migrants. Very few studies adopt such a systematic approach to the contact phenomenon and instead proceed as if the effect were uni-directional, impacting as it were on the newcomer only (24).

Only recently has the experience of the host community --specifically the host families--become a subject for 
discussion and research. Most of this has been of an exploratory nature, describing the experience of the host families and developing some preliminary principles and conclusions. For the most part it is pre-theoretical, consisting of interviews and/or surveys of host families, foreign visitors, program administrators and occasionally teachers of foreign students (Van de Water 1970; Gorden 1974; Hartung 1983; Bennett 1985; King \& Huff 1985; Grove 1988) But more systematic study and analysis of the host family experience is necessary to bring the "reverse side of the intercultural equation" into balance.

\section{PURPOSE OF THE STUDY}

The purpose of this study is to note the established goals of international exchange as defined in the literature and to determine whether they are shared by the host families who participate in a typical homestay exchange program. The issues being researched are why, from their perspective, host families participate in international exchange and if they perceive the established goals as relevant to their experience.

Fairly well-defined goals of international exchange have been established and will be discussed in the next chapter. These goals are often assumed to be significant for program administrators, sojourners and host nationals alike. Because so little is known about host families, 
however, this assumption is not necessarily valid. If host families do not share these goals, or rank them in different order of importance, we need to learn what their goals are and how they rank them. It is necessary to know if there is congruence or divergence between theory and practice.

As Babbie (1986) states, "much of social research is conducted to explore a topic, to provide a beginning familiarity with that topic." Exploratory studies, he continues, are appropriate "when a researcher is examining a new interest or when the subject of study is itself relatively new and unstudied" (72). Research on the experience of host families has been minimal at best. For that reason, this project is designed as a small-scale exploratory study. The intention is to generate data by which the host family experience can be described, providing at least approximate answers to the following four research questions :

1. What are the goals of international exchange as established in the literature?

2. What are additional goals of international exchange that are not discussed in the literature?

3. To what extent are any of these goals important for host families?

4. In terms of these goals, how do host families evaluate their experience?

Finding answers to these questions is essential to a more adequate preparation of host families for the responsibilities they will assume when sharing their homes and 
life-style with a foreign visitor. Identification of family priorities is important so that programs can be developed both to meet the accepted goals of international exchange and to satisfy the needs of those who help make homestay exchanges possible.

\section{ORGANIZATION OF THE STUDY}

Chapter II presents a brief review of the literature on international exchange regarding the effect it has had on the host culture and identifies goals of international exchange as established and defined by researchers in the field. How the survey instrument was created, selection of the respondents and data analysis procedures are given in Chapter III. Chapter IV provides a demographic analysis of the respondents and analyzes the data obtained through their completed questionnaires. The discussion includes: Evaluations for the level of importance of each goal represented in the survey instrument as rated by the respondents; determination of whether the items rated high in importance represent goals established in the literature; and an analysis of how the host families evaluated their hosting experience in terms of the goals they rated high in importance. Chapter $\mathrm{V}$ summarizes the findings. It discusses their implications and considers their application to the development of future homestay programs. It concludes with suggestions for future research. The 
appendices include cover letters for both the pilot and final study, and parent/guardian and sibling questionnaire forms. 


\section{CHAPTER II}

\section{REVIEW OF THE LITERATURE}

Research in international exchange has focused primarily on the effect of intercultural contact on the sojourner with little attention given to the experience of host nationals. Much of the resulting literature has discussed the "contact hypothesis," described by Selltiz and Cook (1962) as a widely held assumption that getting to know the people of another culture or racial background will lead to liking each other, will change stereotypes for the better, will increase international good will and reduce tensions $(10)$.

In the same article, Selltiz and cook challenge the validity of this assumption, as have many other researchers (Hofman \& Zak 1969; Amir \& Garti 1977; Kagitcibasi 1978; Hanvey 1979), all of whom maintain that positive intercultural interaction is dependent upon a multitude of interdependent contact variables. In a summary of research on the contact hypothesis in ethnic relations, Amir (1969) concludes that the most significant variables hold only under the following conditions:

1. When there is equal status contact between members of various ethnic groups. 
2. When the contact is between members of a majority group and higher status members of a minority group.

3. When an "authority" and/or the social climate are in favor of and promote the intergroup contact.

4. When the contact is of an intimate rather than a casual nature.

5. When the ethnic intergroup contact is pleasant or rewarding.

6. When the members of both groups in the particular contact situation interact in functionally important activities or superordinate goals that are higher ranking in importance than individual goals of each of the groups (338).

That the process of intercultural contact is significantly more complex than indicated by the contact hypothesis leads Sherif and Sherif (1953) to argue that "in any discussion on the effects of contact on intergroup attitudes, we must specify: what kind of contact? contact in what capacity?" (221). Amir and Garti (1977) agree with this approach when they state, "Clearly, the outcome of ethnic contact depends upon conditions prevailing at the time of contact, and conditions of both situational and personal nature" (58).

Like Bochner (1982), Paige (1983) recognizes the need for more studies on the host culture's intercultural experience. He is critical of the insufficient attention given to the effects of intercultural contact on the majority or host culture. In so doing, he is one of the few in the field of intercultural communication who recognizes this as a problem for understanding the causes and consequences of cultures in contact. 
He questions the dominance of the contact hypothesis in the literature, even when "refined operationally into discrete dimensions" (109). Such "single-cause-and-effect theories" are, in his opinion, too limited in their explanatory potential. Instead, he proposes a multivariate model in which intercultural contact is "only one of many theoretically plausible explainers of intercultural cognition, affect and behavior." Researchers, he says, "must set contact into a more elaborate context of rival explanatory concepts" (109). Drawing upon the theoretical literatures of psychology, sociology, social psychology, intercultural communication, anthropology and other fields, he identified several relevant variables and grouped them into the following categories which comprise the framework of his model:

1. Variables internal to the human environment:

These include: commonality of goal orientation; the nature of institutional support; the characteristics of the social climate; the degree of fit between person and environment; the degree to which the milieu inhabitants view their self esteem as being promoted; the presence of stereotypes and attributes based on selected status characteristics such as foreignness or race; peer-group support for intercultural contact; the presence of own culture support groups as "refuge settings" during times of extreme culture fatigue; and competition for resources such as financial aid for students.

2. Personal characteristics or traits of the milieu inhabitants. These include: age; sex; college major; political orientation, prior work/study/ travel abroad experience; worldmindedness or "global awareness"; participation in and attitudes toward international programs; interest in intercultural contact; and a variety of frequently 
discussed traits such as empathy, tolerance of ambiguity, openmindedness, and a culturally relativistic world view.

3. External factors, which include: international crises; changes in international relations; and political upheavals and related events (109-10).

The value of his model, Paige contends, is that it permits better conceptualization of both dependent and independent variables and expands upon the contact hypothesis by "locating contact within a multivariate framework of other explanatory variables" (111). It also provides a frame of reference for an examination of intercultural learning in either the host or sojourner population because these variables are relevant to all the participants in intercultural situations.

Before the 1970s, when interest in the host culture increased significantly, two minor studies were conducted whose main concern was with host families. One study conducted by The Experiment in International Living (Somer, et al. 1959 ) explored the problems of predicting and evaluating "success" as experienced by American students participating in The Experiment's homestay programs. This study involves interviews with 74 European families for the purpose of recording their reactions to their foreign guests. The guests, who were students, were also interviewed, and their responses were compared to those of their host families. Questions were of a general qualitative nature and included descriptions of host family criticisms of the American 
students and the level of understanding achieved by both the family and the guest. However, this study did not produce much in the way of detailed data from which significant comparisons or conclusions could be drawn.

The second study, carried out by A.M. Khan (1961, as quoted in Van de Water 1970), an East Pakistani researcher, consisted of administering a simple questionnaire to 29 host families in East Pakistan and to 29 Peace Corps volunteers who stayed in their homes. The purpose of the survey was to "assess the opinions, reactions and the level of acceptance of the Volunteers by their host families" (26). The study concludes that the experience was more rewarding to the volunteers than to their host families, largely because the families did not partake in the planning or programming and did not have the orientation they thought was necessary to prepare them for their participation in the program. Khan does not intend this to be an empirical research document and cautions against drawing any premature conclusions.

Other studies exist that include the host family component, but their main concern has been to explain how the sojourner is affected by his or her intercultural experience. Usually this research focuses on the processes of adjustment (Schild 1962) and attitude change (Kelman 1962; Selltiz \& Cook 1962; de Sola Pool 1965; Hofman \& Zak 1969 ) or the role of social interaction and close 
bi-national friendships (Goldson, suchman \& Williams, Jr. 1956). These studies do not, however, isolate the host family as a subject for examination.

Since the 1970s a small but growing interest in the experience of host nationals has emerged. Van de water (1970) broke some ground in his unpublished doctoral dissertation on American exchange students living with host families in Italy, France and the Netherlands. This is a comparative evaluation of three Syracuse University foreign study programs whose stated purpose is an evaluation of "the American college student-foreign host family relationship as part of a foreign study program" (20). Of seven hypotheses Van de Water sought to verify, one is relevant to this project. It reads:

Hypothesis 6: There is a significantly high correlation between the motivation of the family in acting

as a host and the student-host relationship.

Using a list of nine motivation items (which will be discussed more thoroughly later in this chapter), he asked both the students and their host families to rank them for significance. Correlation of their responses confirmed his hypothesis. Van de Water cautions against drawing false or premature generalizations from his findings and concludes that they "should be considered unique to the Syracuse University programs which were the source of the data" (95). He notes that as a first study on this subject, his data are unique "in that they appear to be the outcome of the only 
available empirical attempts to examine the significance of placing American college students with foreign host families" (3). Therefore, he recommends further research and replicative studies to verify his findings.

In 1974, Gorden published a book describing cross-cultural misunderstandings that arose between host families in Bogota, Colombia, and American students and Peace Corps volunteers living in Bogotan homes for as long as six months. This study reports the kinds of non-verbal communication problems Americans had in their hosts' homes due to mutual misunderstanding of each other's non-linguistic cultural systems (viii). Gorden gathered his data through extensive interviews with both visitors and hosts. One significant phenomenon he identifies through these interviews is the "importance of developing a cultural context for communication" (vii). He cites three major findings that he views as running "counter to some of the simplistic assumptions regarding the nature of the cross-cultural process" (3). These are:

1. Goodwill and intelligence are often helpful but not enough.

2. Facility in the foreign language is necessary but not sufficient to guarantee cross-cultural communication

3. Seemingly trivial misunderstandings often lead to basic mutual misperceptions and generate hostility or alienation (3).

His findings, he hopes, will "prove some insight into the general principle that the interpretive context for any 
dialogue is contained in the social situation in which it takes place" (12).

A third study that considers host attitudes is a TESOL master's thesis project done by a UCLA graduate student (Hartung 1983). Her purpose was "to create a framework for the construction of orientation materials for Japanese high school students planning to come to America for one-year [AFS] homestay programs" (4). As part of her research, she interviewed the host families as well as the students and their teachers in order to identify socio-cultural situations which cause conflict between the visiting students and their hosts.

Although her main concern was providing the visiting Japanese students with better orientation materials, her interviews with host families reveal unmet needs on their part, too. They did not feel they were adequately prepared for problems that developed through cultural differences and they wanted more specific information about the Japanese culture. She recommends providing the families with more culture-specific materials to supplement the culture-general training and handbook provided by AFS. Based on responses from the students, their host families and teachers, she developed extensive lists of advice for each to aid in their dealing with problems of cultural communication. Her data were explicit enough that it could be directly quoted and included in future orientation materials. She identifies 
several socio-cultural situations which cause special stress for the students, pointing out that these "major differences exist at the cultural level rather than as a result of personal idiosyncrasies" (145).

By incorporating the perceptions of both hosts and guests, Hartung makes a valuable contribution to understanding the complexity of human relations that are a result of international exchange. Her work represents a growing awareness of the interdependence of all participants in the exchange phenomenon.

The year after Hartung completed her work, Grove (1984) published a preliminary research report on the dynamics of international hosting. His was the first to focus entirely on host families. It is a longitudinal, exploratory study that utilizes in-depth interviews with 15 host families over the course of more than a year. He and his research team plotted each family's "relational and emotional fluctuations" throughout the year they served as a host family. From these interviews, he draws several principal conclusions, which include:

1. The course of a student-host relationship depends more on personality factors than on cultural factors.

2. A satisfying experience frequently depends more on student-host-sibling relationships than on student-host-parent relationships.

3. A satisfying experience is far more likely when the exchange student is willing to participate wholeheartedly in family activities. 
4. When the exchange student is in frequent telephone contact with members of his or her natural family the hosting experience is seriously undermined.

5. An authoritarian personality on the part of one or both parents creates a highly structured situation that most exchange students find difficult to fit into $(26)$.

of these conclusions, the first is controversial, running contrary to current thought in both intercultural communication and social psychology. Experts in both disciplines hold to the view that while individual personality factors, or traits, are important, cultural factors are the most significant in cross-cultural contact (Hall 1959; Brislin 1981; Barna 1982; Dinges 1983). Condon and Yousef (1975) dismiss the notion of the "universal communicator" as a myth and challenge the belief that there are certain people who will be acceptable in all cultures (252). Brislin states, "The usefulness of traits...is a hotly debated topic at this time" (53). Grove's conclusion adds heat to the argument as it can lead to the assumption of psychological universals, thus denying difference, i.e., "that cultures differ fundamentally in the way they create and maintain world views" (Bennett 1986, 27-8). This is a key organizing concept of intercultural sensitivity, the denial of which can reduce sensitivity and decrease effective intercultural communication in general. Given the scarcity of research about the host culture, it remains to be seen if further studies in the area will validate Grove's controversial conclusion. 
In 1985, King \& Huff published the Host Family Survival Kit: A Guide for American Host Families. It is, they state, "a first attempt to describe the homestay experience from the host's perspective" (xviii). No hard data are available about "typical" or "average" host families on which they could base their observations. They drew upon what research was available, particularly Grove's, and interviewed several selected host families who, in their opinion, "have been highly effective and successful" (xvii). Their intention was to produce "a practical guide rather than an academic study," and the book is written in an informal style easy for the layperson to understand.

It is a descriptive account of the hosting experience that provides host families with information on how to deal with problems that might develop between them and their foreign guests. Much of their discussion deals with the process of culture shock as experienced by the sojourner. King \& Huff also introduce an interesting and complementary concept they call "exchange-itis", which represents a kind of intense and sometimes upsetting reaction that the family can go through "as a result of having in their home a person who represents a totally different way of life" (30). They equate this with the culture shock phenomenon commonly experienced by a foreign visitor and suggest several ways to recognize and deal with it. 
King and Huff utilized a methodology similar to Hartung's, interviewing hosts and guests and incorporating the perceptions and reactions of both in their results. This is a new and welcome approach that represents a growing awareness of the significant role host families play in creating effective international exchange. Such research is still in its embryonic state, and as the authors state in their introduction, "this effort is merely a beginning point. Other writers will surely augment and revise what is said here" (xvii). By entering a new phase of inquiry they have expanded the research in international exchange and met an important need in the field.

Goals of International Exchange As Defined In The Literature

Fairly well-defined goals of international exchange have been established. Responding to the dramatic increase in exchange programs that occurred in the 1950s, sponsoring institutions were the first to express explicitly what these goals are. They were summarized in a report prepared in 1955 by the Committee on Education Interchange Policy of the Institute of International Education (IIE). In order of frequency, they are:

1. To promote international understanding and good will among the peoples of the world as a contribution to peace.

2. To develop friends and supporters for the United states by giving persons from other countries a better understanding of the life and culture of the United States. 
3. To contribute to the economic, social, or political development of other countries.

4. To aid in the educational or professional development of other countries.

5. To advance knowledge throughout the world for the general welfare of mankind (Gullahorn \& Gullahorn (1958, 369).

Although some have questioned these goals as unclear and/or ambiguous (Abrams 1961; Coelho 1962; Mishler 1965), for the most part they remain applicable to the present day. Kelman (1962) defines the purpose of international exchange as "creating good will and creating favorable attitudes across national boundaries" (73). Paige (1983) views intercultural contact as providing opportunities for intercultural communication, relations and contact. He says:

From these opportunities can emerge new knowledge about oneself and others (cognitive learning), a higher level of global knowledge (cognitive learning), empathy and a greater appreciation of the aspirations of others (affective learning), and new behavioral repertolres for functioning in intercultural communication situations (behavioral learning) (106).

Thirty years after the IIE outlined their list of goals, Rhinesmith writes in a similar vein that the goals of international exchange are "International understanding for the maintenance of peace, the acquisttion of skills and knowledge, and the transfer of technology and professional expertise and personal development," stating that these "undergird the international exchange movement in the United states today" (14). Although the language of these goal 
statements reflects the times when each was written the spirit of the content is that of the IIE.

Bennett (1985) identified an additional set of goals in her unpublished doctoral dissertation that investigates an intercultural communication training program she conducted for the Northwest Interinstitutional Council on Study Abroad (NICSA). This is one of the few studies that utilizes a comparative approach. As part of her study, Bennett surveyed 181 study abroad students and the NICSA Council, which consisted of a staff member from each of 14 colleges "who comprise the NICSA consortium, either serving in the role of representative or campus contact" (71). She compared their responses to determine to what degree they agreed on program goals for study abroad. Drawing both from preliminary interviews with the Council and the goals most frequently cited in the study abroad literature (Abrams 1960, 4-5; Coelho 1962, 56; Mishler 1965, 557-8; Carroll 1974, 30) she identified six goals that were included in her questionnaire. They are:

1. To stimulate academic achievement in an environment relevant to the subject.

2. To provide an opportunity for intensive foreign language study.

3. To increase awareness of the students' role in his or her own culture.

4. To achieve understanding of another culture.

5. To encourage personal development.

6. To broaden a liberal arts education. 
Bennett asked the Council members and students to complete a questionnaire in which they rated these goals on an anchored interval scale, ranging from "not at all important" to "very important." In her analysis of their answers, she found:

1. Students and the Council were in agreement in ranking knowledge of other cultures as the pre-eminent goal of the program.

2. The Council ranked the goals of broadening education significantly higher than the students, putting it in second place after understanding other cultures. In contrast, the students ranked this goal the lowest.

3. There is a high degree of consistency on the part of the students and the Council in the valuation of all goals except the broadening of education

4. The students share the goals of the organization, but tend to place personal goals first, ranking academic achievement, language learning and broadening their education lower in importance (73-8).

Two studies have included a survey of host families to determine what motivated their participation. While it can be argued that motivation is not the same as a goal, so little research has been done on this subject that it seems relevant to include these studies in this review. The first of these is Van de Water's doctoral dissertation (1970). In his introductory remarks, he raised some basic questions to which he sought answers. One of these is, "What do the student and host family state is the primary motivation of the family in hosting a student?" (34). To answer this, he developed a list of nine motivational items to be ranked by both the families and their visiting students. These items 
are quite specific in nature, asking if families acted as hosts to American college students because:

1. They needed the additional income.

2. They are interested in learning about Americans.

3. They want to improve their English.

4. They want to promote international understanding.

5. They want to show Americans the manner in which people live in their culture.

6. They want to assist Americans in learning a foreign language.

7. They want to promote political ideas in which they believe.

8. They feel it is a valuable experience for their children.

9. They are interested in making new friendships $(65)$.

When discussing the families' and students' responses, Van de water does not directly answer the question he asked. He utilizes his data instead to validate a hypothesis that poses a correlation between host motivation and a satisfactory host-student relationship. still, the motivational items he developed were useful to this project and, in conjunction with those of the IIE and Bennett, were incorporated into a survey instrument that is discussed in the following chapter.

The second of these two studies was conducted in 1987-88 (Torrey \& Wheeler 1988) as a project for the United States Information Agency (USIA). The purpose was to gather current statistical information about youth exchange programs so as to address the problem of: 
a reported decline in the number of available homestay host families, which by some reports is associated with a "saturated" market for teenage exchanges and/or an alleged decline in the quality of homestays offered exchange students (5).

The study included hour-long telephone interviews with administrators of exchange organizations and structured questionnaires mailed to recommended host families, community representatives, foreign students and selected school officials. It provides a wealth of information on "background, issues and expected accomplishments set forth by the USIA" (2). The authors' statistical compilations are extensive, but they provide little significant discussion of their findings.

One question in their survey is directly relevant to this project. They asked, "Why do you think families are willing to host students today?" (28). The possibilities were:

1. Foreign exposure

2. U.S. goodwill ambassador

3. Own homestay experience

4. Companionship for children

5. Prestige

6. Help world understanding

7. Love of children

8. Sharing way of life, home

9. Children request

10. Mother's encouragement

11. Educational experience 
The authors report the total number of positive responses item-by-item and provide a one-sentence interpretation for each. In their overall summary they discuss why families won't host (10) with no elaboration on why they will. It is an extensive report but unfortunately provides little more than interesting raw data. Their report was published after the survey for this project was completed, however, and was not drawn upon when the survey instrument was developed.

The last study to be considered is one completed by Lowe, Askling and Bates (1984). They note how rarely the contribution that host families make to international exchange and education has been evaluated. Their purpose is to remedy this by evaluating the usefulness of the host family component in developing four major dimensions of intercultural contact. These are: personal development, intimacy, international networks, and a better understanding of foreign affairs.

Through a questionnaire survey, the authors investigated how 196 host families from the Council of International Programs for Youth Leaders were affected by their participation in a professional exchange program which, on the average, lasted for three to four weeks.

They state, "A goal of many exchange programs is the development of intimacy and friendship between host families and exchange participants (Brislin, 1981; Kelman, 1975)" (56). Determining whether this goal was achieved by the 
host families is a significant part of their study. They conclude that it was, and that as a result families are affected in four ways. These are:

1. They changed their attitudes and increased their interest in and understanding of cultural difference.

2. Participation develops intimate relationships between host and exchange participants.

3. Participation develops international networks of people concerned about world issues and problems.

4. Host families develop better understanding of foreign affairs and often participate in the decision making of their nation's foreign policies (45).

Their findings provide strong evidence that host families achieve the general international exchange goal of developing intimate and long-lasting relationships with their foreign visitor. Whether or not the host families perceived this as their goal is not an issue the authors address.

\section{LITERATURE REVIEW SUMMARY}

The research related to international exchange focuses primarily on various aspects of the sojourner's experience. Despite the increasing popularity of homestay exchange visits, there is little reported data available directed toward the experience of the host families. A few researchers in the field recognize that the host family component needs systematic description and analysis so as to fully understand the causes and consequences of cultures in 
contact. But no cross-sectional studies have yet been published and only a few exploratory studies have been completed. Because inquiry in this direction is new, little theory has yet been developed around the experience of host nationals when interacting with exchange visitors.

A brief survey of the literature identified several established goals of international exchange. As with the research in general, studies regarding these goals have concentrated on their importance for sponsoring institutions and/or sojourners but have overlooked their significance for host families.

As the number of homestay programs increases, the need to understand the host family's role becomes more important. It is the purpose of this project to address that issue. The goals that have been identified in this review were used to create a survey instrument designed to determine why host families host. How this instrument was developed and the methodology of this project are the subjects of the next chapter. 
CHAPTER III

METHODOLOGY

As stated in Chapter I, this is an exploratory study designed to describe the experience of host families. The specific purpose is 1) to determine whether host families perceive as relevant those goals established in the international exchange literature; 2) to identify those goals, if any, they perceive as relevant that are not discussed in the literature; and 3) to assess how, in terms of these self-identified important goals, the host families evaluate their experience.

In view of this purpose, the project was designed and carried out in the following manner.

\section{DESIGN OF THE STUDY}

Because I wanted to know the personal attitudes of host family members, a survey utilizing a written questionnaire was chosen as the appropriate technique for gathering information that does not exist in public records or documents. A survey was the best way to gather the information directly from people who possess the data (Tucker, Weaver, Berryman-Fink 1981, 92). 
To reach the largest number of people involved in hosting, a self-administered questionnaire was utilized. I considered administering each questionnaire myself, or with a trained survey crew, but considerations of time and a lack of competent interviewers precluded this decision. In-depth interviews with a smaller number of selected host families was another possibility but was dismissed for the same reasons. Personal interviews would have allowed me to probe more deeply for answers and act as a guard against confusing questionnaire items. But for the purpose of this initial exploratory study, breadth of response versus depth was sufficient. Furthermore, asking busy host family members to complete their own questionnaires was thought to be more convenient for them and less of an imposition on their time than asking them to participate in lengthy personal interviews. This was an important concern when considering an adequate response rate.

\section{INSTRUMENTATION}

Two questionnaires were created, one for host parents and a modified version of the same for host siblings. (See Appendix A.) The questionnaires consisted of three parts. Part I was divided into eight categories of closed questions dealing with goals. Avoiding open questions eliminated the need to subjectively interpret the data, and thus all statistical analysis could be done numerically. The parent 
questionnaire included 43 questions. The sibling questionnaire was identical to the parent, with the following exceptions: 1) Four questions were reworded to be more applicable to siblings; and 2) five questions were omitted because they did not apply to siblings. With the omission of these five items, Part I of the sibling questionnaire included 38 questions.

Each question consisted of two parts. Part A asked, "How important was the following goal or objective for your participation in the program?" When answering this part of the question, the respondents were asked to consider how they felt before their guest's arrival. Part B asked, "To what extent was this goal or objective accomplished?". When answering this part they were asked to evaluate how they felt after their guest's departure. The purpose of asking a two-part question was to determine how the participants evaluated their experience in terms of those goals they thought were important.

Participants were asked to rate their responses on a seven-point Likert-type scale. The numbers progressed from a minimum of one to a maximum of seven. For Part $A$, the scale was anchored, with one being "not important" and seven being "very important". For Part B, the scale was anchored, with one being "not at all" and seven being "to a great extent". 
Because all the questions in Part I were closed, Part II was designed to allow respondents to express themselves more freely. One open question was asked, encouraging them to discuss any additional factors other than those mentioned in Part I that they regarded as relevant to their volunteering as a host family. A section for additional comments was also provided.

Part III provided background information (demographic data) on the respondents.

All of the questionnaires were confidential.

\section{Origin of The Survey Questions}

The 43 questions used in this instrument were drawn from several sources. Twenty-one were based on the established goals and motivational items cited in the literature review. Twenty-two were derived from interviews with homestay coordinators, former host families, and my own colleagues and friends. All were asked to speculate as to why they or others might participate in a homestay exchange program. From their input, I developed a list of tentative goals that might be the basis for additional questions.

To confirm this list, I then interviewed a small sample (6) of experienced host families, asking them, too, why they became involved in hosting and to speculate on the goals of others. Goals they mentioned often that had not been suggested previously I added to the list, assuming if 
they were important to these experienced individuals, they also might be important to host families in general. I also utilized these interviews to gain a general sense of how well host families were comprehending the project.

Out of all these suggested goals, I selected those that appeared most frequently and developed a final list of goals not mentioned in the literature. From these I formulated 22 non-literature-based questions that were included in the final questionnaire.

The 43 questions tapped a broad range of experiences which were arranged into the following eight subsections: 1. Interpersonal Relationships (1-4); 2. Family Issues $(5-11) ; 3$. Guests as a Resource $(12-16) ; 4$. Personal Factors $(17-22)$; 5. Educational Opportunities (23-29); 6. Community Involvement (30-32) 7. Developing Values and Attitudes (33-37); 8. Expressing Your Philosophy of Life (38-43). These categories were not evaluated and designed for purposes of later analysis, but rather to help make sense out of the questionnaire for the respondents. The questionnaire was lengthy ( 13 pages), and needed to be divided into these subsections to make it more interesting and less fatiguing to complete, thereby motivating the respondents to answer all the questions. It might have been useful to have also introduced each subsection with a short explanatory statement to make sure that the respondents were clear as to its content and purpose (Babbie 1986, 209-10). 
For the purposes of this study, it was necessary to distinguish those goals that were derived from the literature from those that were not. Therefore, a brief discussion of each question follows. It should be remembered that all questions were asked in the form of, "How important was it for you...?" and, "To what extent was this accomplished?"

\section{Literature-Based Questions}

Question number 1 asks: How important was it for you to establish a long-term relationship with someone from another culture? This was based on Lowe, et al.'s study, in which they state that a goal of international exchange is developing intimate relationships between host and guest which are expected to last after the programs ends.

Question number 2 asks: How important was it for you to allow your children to interact with people from other cultures? It was based on the NICSA goal, "To achieve understanding of another culture" and on Van de Water's motivational item, "They feel it is a valuable experience for their children". This question was omitted on the sibling questionnaire.

Question number 3 is similar to number 2 , but addresses the needs of the respondent only rather than what he/she wanted for his/her children. It asks: How important was it for you to interact on a personal level with someone from a culture in which you are specifically interested? 
Question number 4 came from King and Huff's Host Family Survival Kit. It asks: How important was it for you to share your family's life-style with someone from another culture? The authors consider this goal and wanting to provide a helping hand as the two basic elements in hosting a foreign student (9).

Three questions, numbers 17, 18, and 19, were based on the NICSA goal, "To encourage personal development." It was asked in three different ways to address the personal development of the host parent, host children and foreign guest. Question number 17 asks: How important was it for you to further your own personal development?; number 18 asks: How important was it for you to further family members' personal development?; and number 19 asks: How important was it for you to further your guest's personal development?

Educational opportunities are a significant issue in Bennett's study. Two of the NICSA goals stress academic education, in particular "to stimulate academic achievement in an environment relevant to the subject" and "to broaden a liberal arts education." However, defining a liberal arts education, she comments, is a "thorny issue in the halls of academe" $(80)$. Hence, she breaks this goal down into the "more manageable parts" of mastery of a foreign language, furthering academic achievement, personal development, cultural self-awareness and knowledge of another culture. 
All but one of these goals became the basis for questions in the survey instrument. Academic achievement was not addressed in this project because the programs that respondents were involved in had no academic element. Question number 23, then, asks about an educational experience, but only in the most general terms. It asks: How important was it for you to have an educational experience through hosting someone from another culture?

Question number 24 asks: How important was it for you to achieve understanding of another culture by bringing someone into your home who knows about that culture? This was suggested by the NICSA goal, "To achieve understanding of another culture" and by van de Water's motivational item, "They are interested in learning about Americans."

Questions number 25 and 26 deal with mastering a foreign language, which is one of the "manageable parts" Bennett identifies as a NICSA goal. It is also implied by van de Water's motivational item, "They want to improve their English." Question number 25 asks: How important was it for you to learn or practice the language of your guest? Number 26 asks: How important was it for you to provide your guest with an opportunity for intensive foreign language study?

Question number 27 makes more personal the IIE goal, "To aid in the educational or professional development of other countries," by asking: How important was it for you 
to aid in the educational or professional development of your guest?

Another of the NICSA goals, cultural identity, was addressed in question number 28. It asks: How important was it for you to sensitize your guest to his/her own cultural identity?

Question number 34 asks: How important was it for you to provide members of your family with the opportunity to change their views of people from other cultures? This was based on Lowe, et al.'s conclusion that host families "changed their attitudes and increased their interest in an understanding of cultural differences."

Cultural identity was again addressed in question number 35, which asks: How important was it for you to learn about Americans from the perspective of a person from another culture?

Question number 36 was based on the IIE goal, "To develop friends and supporters for the United States by giving persons from other countries a better understanding of the life and culture of the United States," and Van de Water's motivational item, "They want to show [their guests] the manner in which people live in their culture." It asks: How important was it for you to show someone from another culture the good things about your values and the American way of life? 
Question number 37 is related to number 36 , but is more specific in its orientation. Based on van de Water's motivational item, "They want to promote political ideas in which they believe," it asks: How important was it for you to develop friends and supporters for the American way of life by giving persons from other countries a better understanding of our political system?

Questions number 40 and 41 were based on the IIE goal, "To advance knowledge throughout the world for the general welfare of mankind." They were divided into two questions so that the goal could be applied to both the host family member and the visitor. Question number 40 asks: How important was it for you to increase your intercultural knowledge for the general welfare of humanity? and number 41 asks: How important was it for you to increase your guest's intercultural knowledge for the general welfare of humanity?

There seems to be a general consensus in the literature on the significance of international understanding. The IIE states as their first goal, "To promote international understanding and good will among the peoples of the world as a contribution to peace." Van de Water lists this as, "They want to promote international understanding," and Rhinesmith speaks of "international understanding for the maintenance of peace." Based on these sources, question number 42 asks: How important was it for you to promote 
international understanding and good will among the peoples of the world as a contribution to peace?

The final question, number 43, was based on the IIE goal, "To contribute to the economic, social, or political development of other countries." It asks: How important was it for you to provide an opportunity to an individual from a less developed society who can return and contribute to the economic, social or political development of their own country?

These 21 questions comprise that part of the questionnaire that deals with goals taken from the literature. The remaining 22 questions were derived from other sources and are not usually discussed in the literature.

\section{Questions Based on Sources Other Than The Literature}

Two volunteer exchange coordinators from the American Heritage Association and two from the International Exchange Forum, six experienced host families recommended by these coordinators, and two graduate students of intercultural communication from the Speech Department at Portland State University were interviewed for their suggestions as to why people participate in homestay programs. To stimulate their thinking, I asked these four questions:

1. What were or would be your own goals?

2. What, in your opinion, motivates others to host?

3. What might be goals that lead to an unsuccessful experience? 
4. Others have suggested [their children wanted to participate in an exchange program; they felt they were promoting world peace, etc.]. What is your impression of this goal?

The following 22 questionnaire items reflect their answers. of these 22, four were omitted from the sibling questionnaire and five were reworded in language more appropriate for children.

All of the coordinators and several host family members felt that hosting provided families with an opportunity to increase family "togetherness" by sharing this unusual experience. Therefore, question number 5 asks: How important was it for you to bring your family closer together by sharing the hosting experience? and question number 6 asks: How important was it for you to strengthen your marriage? Question number 6 was omitted on the sibling questionnaire.

Many of the host parents felt that unsatisfied parenting needs might motivate families to volunteer. They had in mind childless adults or those whose children no longer live at home, parents with single-sex children, and only children or those with single-sex siblings. Questions number $7,8,9$ and 10 were based on these speculations.

Question number 7 asks: How important was it for you to experience being parents because you do not have children of your own? This was omitted on the sibling questionnaire. Question number 8 asks: How important was it for you to experience parenting a girl/boy because you do not have a 
daughter/son of your own? This was reworded on the sibling questionnaire to read, ...to experience having a sister/ brother because you do not have one of your own?

Question number 9 asks: How important was it for you to have another young person around for a while because your own children no longer live at home? This was reworded on the sibling questionnaire to read, ...because there are no other children living at home with you and your parents?

Question number 10 asks: How important was it for you to provide companionship for your child? This was omitted from the sibling questionnaire.

The desire to respond to other family members' interest in hosting was mentioned by both the coordinators and the host families. Hence, question number 11 asks: How important was it for you to please your child/ren who heard about hosting and wanted to volunteer? This was reworded on the sibling questionnaire to read, ...to please your parents who had heard about hosting and wanted to volunteer?

One coordinator was familiar with families who thought the presence of an exchange visitor might "straighten up" their own children. Question number 12 reflects this possibility. It asks: How important was it for you to bring a distinctive individual into your home who may act as a positive role model for your own children? This was omitted from the sibling questionnaire. 
That host families might view exchange visitors as a practical resource was mentioned by all the coordinators. For this reason, question number 13 asks: How important was it for you to have a guest who would add to family income? Question 14 asks: How important was it for you to provide additional household help? and question number 15 asks: How important was it for you to provide help in taking care of your own children? Number 15 was reworded on the sibling questionnaire to read, "...to provide help in taking care of other children in the family?"

Several host family members identified traveling to their visitor's country as one of their goals. This is reflected in question number 16 which asks: How important was it for you to visit your guest's country in the future? Some had sojourned previously through an exchange program and were very enthusiastic about the experience, wanting to share it with others. Question number 20 asks: How important was it for you to provide this opportunity for someone else because you participated in an exchange program yourself?

Question number 21 asks: How important was it for you to have fun? This was a goal mentioned by almost all those interviewed.

A few of the coordinators felt that hosting is an unusual experience and that some families might be curious to discover what it is all about. This suggested question 
number 22, which asks: How important was it for you to satisfy your curiosity about hosting?

One host father thought that hosting someone from his own cultural background was a way to learn more about himself. With this in mind, question number 23 asks: How important was it for you to learn about your own heritage better?

Many of the families and coordinators felt that the influence of friends, peer pressure and/or the desire for prestige in the community had an effect on families volunteering to host. Questions number 30,31 and 32 are based on this input. Question number 30 asks: How important was it for you to share the experience of others in the community who have had a good hosting experience? Question number 31 asks: How important was it for you to agree to requests from program coordinators who asked you to fill in as a host family? and question number 32 asks: How important was it for you to do something that will allow you to be well thought of in the community?

The two graduate students suggested that host families might be expressing their sense of individuality and uniqueness, values that are deeply embedded in the American culture. This is explored in question number 33 which asks: How important was it for you to do something different, to accept a risky and unpredictable challenge? 
It is not uncommon for host families to be recruited from church organizations. Therefore, I felt it was necessary to include a question pertaining to religious beliefs in the survey. Question number 38 asks: How important was it for you to put your religious principles into practice?

The final question to come from non-literature sources is number 39. Several host family members mentioned that they found it difficult to travel to other countries and this "armchair travel" satisfied their desire to interact on a personal level with someone from another culture. Thus, question number 39 asks: How important was it for you to have a personal intercultural experience?

These 22 goals complete the questionnaire and provide a basis for determining whether host families become involved in international exchange programs for reasons other than those presently discussed in the literature.

\section{SELECTION OF THE SAMPLE POPULATION}

The respondents in this study were members of 30 host families living in Tillamook County, Oregon, who participated in two homestay programs between Japan and the United States in the summer of 1987. Six of the families were from a 4-H Labo/Lex Exchange Program, and the other 24 had participated in a Host Family Program co-sponsored by the Tillamook YMCA and the Kobe YMCA College in Japan. The age 
range of the visiting Japanese was from 9-19 years, and the length of their visit was three weeks.

Both programs have been on-going for the past 15 years. The Labo/Lex program is designed for very young children, ages 9-12. Most of these visitors come from urban homes, and this is an opportunity for them to experience living on an American farm. This program is a true exchange in the sense that the American host children go to Japan the next year and live with a Japanese host family. This program emphasizes developing an appreciation of the individual and his/her culture through mutual hospitality and understanding.

The YMCA program involves 19 - and 20-year-old Japanese students visiting from a small YMCA college in Kobe. Over the years, this program has gradually changed its focus. Originally, the visitors attended high school classes at Tillamook High School as a formal educational aspect of their American sojourn. Emphasis was on improving their English-language skills which necessitated spending several hours in the classroom and doing about two hours of homework each school night. However, the Japanese students experienced this as a burden because it left them little time for developing interpersonal relations with their host families. Gradually, class attendance was dropped in favor of fun and relaxing activities. Academics have been completely supplanted by recreational family-type activities 
that are designed for joint participation by host family and student.

All of the families live in small (pop. 240-3,000) rural towns in Tillamook County. They were solicited from Tillamook and a few nearby towns on a volunteer word-of mouth basis. Volunteer coordinators screened the applicants based on different criteria for each program, accepting or rejecting them as host families, and assigned the visiting Japanese to suitable homes.

The Labo/Lex program is a $4-\mathrm{H}$ project and only families involved in $4-\mathrm{H}$ were eligible to participate. Because it is designed as a two-way exchange, these host families were required to have a child living at home who was of or near the same age as the visitor and who was willing to sojourn to Japan the following year for a three-week stay with a Japanese host family. Farm families were preferred since a primary purpose of the program is to provide urban Japanese children with an opportunity to experience a rural life-style.

The selection process for the YMCA host families is far more casual than that for the Labo/Lex program. A 35-year-old volunteer coordinator who has hosted several times herself is responsible for selecting the host families. She does so based almost entirely on her personal knowledge about those who apply since Tillamook is a very small town where it is easy to inquire discretely about 
the personal character of individuals who express an interest in hosting. If she does not know the family herself, she checks with others who do and follows their recommendations. She has no specific criteria for selecting host families other than the interest they show and her own intuitive sense of what constitutes a "good" host family. Families are not required to have children living at home, and on one occasion she approved the application of a single man who wanted to be a host father. Hers is a very informal selection process based primarily on the need for as many as 35 host families at one time. So far, she states, she has been "lucky" in her choices.

All families of the Labo/Lex program, therefore, had children living at home. Most of the YMCA families also had children residing at home, but a few did not. Occupations of the adults varied, from dairy farmer and millhand to teacher, Coast Guard commander, housewife and small businessperson. All the families are Caucasian, which allowed for no ethnic diversity.

In the spring Quarter 1987, the local community college in Tillamook solicited my services for teaching a class on intercultural communication with the Japanese, to run concurrently with the exchange visits of both programs and offered tuition-free to all host family members. Through this I became acquainted with the volunteer coordinators. When seeking host families who might be willing to 
participate in this project, I talked to these coordinators who offered to put me in touch with their host families. They provided me with the names and addresses of the families and encouraged them to cooperate with me in this study •

These families were readily available as research subjects. They represent the types of small-town, rural families who volunteer to host and, except for the fact they all live in a rural community are also typical of host families in general (Grove 1984, 3).

\section{PRELIMINARY AND ACTUAL STUDY PROCEDURES}

\section{Preliminary}

In Spring Quarter 1988, a preliminary questionnaire was drafted. In April 1988, I conducted a pilot study with five host families associated with other exchange programs to test for potential problems in the survey instrument. I asked each of these host mothers and fathers to complete individual questionnaires. A sibling questionnaire was also provided for each child in the family who was of school age or older. In a cover letter to the pilot study families, I explained the purpose of the project and asked them for any comments or criticisms they cared to make about the questionnaire design and content. I also told them if they had any problems or if there were items they thought should be added, I would welcome their suggestions. (See Appendix B.) 
In interviews with these families, they reported that some of the language needed to be simplified because it was too "academic" and difficult to understand. It was also evident that siblings under the age of 14 were too young to participate effectively. They found the subject matter to be too complex and tended to guess at answers, thinking they were taking a test and had to answer. Very young children needed to have the questions read or explained to them. Some of the parents viewed this as an imposition, suggesting this might discourage parents from participating in the survey at all. For these reasons, I decided to include only those siblings who were 14 years or older in the final survey.

\section{Actual Study}

Based on this feedback the preliminary draft was modified into its final version. A cover letter to accompany the questionnaires explained that the purpose of the study was to describe the communication process that occurs when international guests and host families live together in a family environment. (See Appendix c.) It pointed out that this information would be useful in developing orientation and training programs that would meet the needs of both visitors and hosts. They were informed that I would telephone in a few days to make arrangements to pick up their completed questionnaires. I also assured them of the confidentiality of their responses and thanked 
them in advance for their cooperation. The cover letter was signed by myself and my thesis advisor.

on July 5, I personally delivered questionnaires to 68 host parents and 23 of out of total 59 host sibling participants. Thirty-six host siblings were not queried because they were less than 14 years of age. A week later, I called on each family again and collected all the questionnaires they had completed.

In September 1988, analysis of the data began. The response rate was: 51 parents (758) and 18 siblings (768). Although there is no fixed point for determining an adequate response rate, 70 percent or more is considered to be very good (Babbie 1973, 165). I attribute this high rate of return to several factors: My involvement in the community and the geographical availability of the participants for individual contact allowed me to deliver and pick up the questionnaires rather than using a mail survey, which provided a personal touch and gave the participants more of a sense of involvement in the project; the host families' general interest in the subject, as evidenced by requests from many respondents for a summary of the results; and the families' enthusiasm about hosting which they enjoyed sharing with someone who was interested in their experience. 


\section{DATA ANALYSIS PROCEDURES}

Because this is an exploratory research project designed to get a sense of what people think, simple descriptive statistics were used to analyze the data in the following manner:

The demographic information reported in Part III of the survey instrument was categorized and discussed to provide an overview of the respondents.

The data collected in Part I were analyzed and ranked according to mean scores and standard deviations to identify which goals were perceived as important by the host families. Participants were asked to mark their responses on 1-7 Likert-type scales, with 1 being "not important" in Part A for importance and "not at all" in Part B for achievement, and 7 being "very important" in Part A and "to a great extent" in Part B. When analyzing the data, I used the following convention to determine importance or achievement, respectively: Questionnaire items that rated a mean score of $\geq 5.00$ were considered as important or achieved by the host families; those items that rated a mean score of < 5.00 were considered unimportant or unachieved.

The distribution of the mean scores for part $A$ of the literature-based questionnaire items was analyzed first and for the non-literature-based items second to determine which goals were perceived as important by the respondents. The 
mean scores for Part B of the questionnaire items, representing achievement, were then compared to the mean scores for Part A to assess how the respondents evaluated their experience in terms of the goals represented by each item. Finally, out of curiosity, a series of $\underline{t}$ tests were applied to the data to test for any differences in response based on the following variables: age, sex, educational level, and family role, i.e., parent or sibling.

Additional comments made by participants in Part II were incorporated into the discussion when necessary to clarify or reinforce the numerical analysis.

The purpose of this study was to identify a body of goals that were regarded as significant by the host family and to determine how, in terms of these goals, host families evaluate their experience, thereby ascertaining if there is congruence between theory and practice. The study, therefore, concludes with the construction of a list of important goals and conclusions drawn from a cumulative impression of the data analysis. 


\section{CHAPTER IV \\ RESULTS AND DISCUSSION \\ HOST FAMILY DEMOGRAPHICS}

The host parents' ages varied widely. The host mothers were from 31-67 years, with an average age of 40 . The fathers were from 34-72 years, with an average age of 44. The ages of the sibling respondents were from 14-26, with an average age of 19. (The ages of the total 59 host siblings ranged from 1-26 years, with an average age of 13.) This age variance of the parents means that it is difficult to describe the "typical" host family. It also indicates that interest in hosting spans several generations.

None of the families were childless, but two of them had no children living at home during the visit. of these, one was an elderly retired couple with grown children and the other had two young children who were temporarily away from home that summer. Several of the families had other grown children no longer living at home. The questionnaire was very clear about how to indicate this when reporting the number of siblings who had participated in the homestay visit.

The highest level of education of the host mothers was very evenly distributed: nine (33\%) indicated graduating 
from high school, nine (338) indicated some college, and nine (33\%) indicated graduating from college. One (1\%) mother reported completing the eighth grade. However, at 67 she was the oldest host mother, and $I$ do not think it is uncommon for people from her generation to have less formal education than is now required and expected. Eighteen (64\%) of the host mothers gave homemaker as their occupation; 10 (368) worked outside the home. Of these, four reported they were teachers and the remaining six included a foreman, sales marketing assistant, delicatessen manager, grocery clerk, medical technician and secretary.

The highest level of education of the host fathers was more widely distributed: one (48) indicated he had finished the sixth grade, two (98) indicated they had attended but not completed high school, six (26\%) reported graduating from high school, one (48) had attended trade school, six (268) indicated they had attended some college, five (228) had graduated from college, and two (98) had attended graduate school. All were employed outside the home, and their occupations reflected a community where the two main industries are dairy farming and logging. These included dairy farmers, a feed plant operator, mill foreman, saw filer, truck driver, forestry technician, engineer, school superintendent, YMCA director, insurance business owner, Coast Guard commanding officer and pastor. 
Nine (50\%) of the sibling respondents indicated they were attending high school, two (11잉 reported graduating from high school, and seven (398) indicated they were currently enrolled in college. All but two reported their occupation as student. The two who were not attending school reported their occupations as a construction worker and a clerk in a department store.

These educational and occupational levels are above average and help to give some idea as to what kind of American family is interested in and can afford to host a guest from another country.

Eleven (39\%) of the families had never hosted before, nine (32\%) had hosted one to three times, and eight (298) had volunteered as host families more than four times prior to the 1987 programs. From these data it is impossible to state how prior experience influenced the host families in evaluating their participation in homestay programs. This will be addressed more fully in Chapter IV where I discuss host family achievement of important goals.

However, the respondents were asked if, based on their previous experience, they would act as a host family again. Of the total 69 respondents, 26 host mothers, 22 host fathers and 16 host siblings reported they would (938). Of the five who said they would not, all gave as their reason a lack of time rather than a lack of interest. Interestingly enough, several of the respondents commented that they had 
had some problems during the visit, primarily because of cultural misunderstandings. That 93 percent were willing to host again may indicate a strong relationship between previous experience and the desire to stay involved in hosting, whether that previous experience was positive or not.

HOST FAMILY RATINGS OF GOALS FOR IMPORTANCE

The purpose of the following discussion is twofold. The first is to evaluate the ratings given by host families to each of the goals represented in the questionnaire to determine which of these are perceived as important. The second is to determine whether or not these represent goals established in the literature. For the sake of clarity, the literature-based data is presented first and the non-literature-based data second.

Several $t$ tests were applied to the data to reveal any differences in response from participants based on the following variables: age, sex, educational level, and family role, i.e., parent or sibling. None of the tests indicated significant differences, and therefore no distinctions are made in terms of these variables when presenting the data.

Ratings of Literature-Based Goals

Table I presents the host family ratings for each of the 21 literature-based questions. The first column lists 
TABLE I

MEAN RATINGS FOR IMPORTANCE OF

LITERATURE-BASED QUESTIONNAIRE ITEMS BY HOST FAMILIES

Questionnaire Item

and Item Number

N Mean

SD

Range

1. Establish long-term relationship

$\begin{array}{llll}67 & 4.79 & 1.67 & 1-7\end{array}$

2. Children interact with guest

$\begin{array}{llll}51 & 6.14 & 1.02 & 3-7\end{array}$

3. Interact with specific culture

$\begin{array}{llll}65 & 5.11 & 1.59 & 1-7\end{array}$

4. Share family's lifestyle

$\begin{array}{llll}68 & 5.51 & 1.26 & 2-7\end{array}$

17. Develop self personally

$\begin{array}{llll}66 & 4.39 & 1.73 & 1-7\end{array}$

18. Develop family personally

$\begin{array}{llll}64 & 4.69 & 1.83 & 1-7\end{array}$

19. Develop guest personally

$\begin{array}{llll}66 & 5.35 & 1.36 & 1-7\end{array}$

23. Educate self

$\begin{array}{llll}67 & 5.13 & 1.81 & 1-7\end{array}$

24. Understand another culture

$\begin{array}{llll}68 & 5.34 & 1.63 & 1-7\end{array}$

25. Practice foreign language

$\begin{array}{llll}67 & 3.16 & 2.10 & 1-7\end{array}$

26. Help guest learn English

$\begin{array}{llll}65 & 3.72 & 1.88 & 1-7\end{array}$

27. Aid guest's educational development

$\begin{array}{llll}67 & 4.64 & 1.86 & 1-7\end{array}$

28. Sensitize guest's cultural identity

34. Change family views of cultures

35. Get guest's perception of Americans

36. Show guest American values/ way of life

37. Develop support for political system

40. Increase knowledge for human welfare

41. Increase guest's knowledge for human welfare

42. Promote international goodwill/peace

43. Ald a less developed society

$\begin{array}{llll}60 & 3.43 & 2.06 & 1-7\end{array}$

$\begin{array}{llll}65 & 4.78 & 1.10 & 1-7\end{array}$

$\begin{array}{llll}66 & 4.48 & 1.99 & 1-7\end{array}$

$\begin{array}{llll}67 & 5.22 & 1.52 & 1-7\end{array}$

$\begin{array}{llll}64 & 3.53 & 2.19 & 1-7\end{array}$

$64 \quad 4.41 \quad 2.14 \quad 1-7$

$\begin{array}{llll}64 & 4.41 & 2.14 & 1-7\end{array}$

$\begin{array}{llll}65 & 5.08 & 1.80 & 1-7\end{array}$

$\begin{array}{llll}50 & 3.10 & 2.16 & 1-7\end{array}$ 
the questionnaire item and gives the number of the item as it appeared in the questionnaire. Columns two through four show the number of respondents, the mean score and the standard deviation for each, respectively. The final column gives the range of scores for each item.

Table II indicates the rank order of the same items. It begins with question 2, "Children interact with guest," valued the highest at 6.14, and ends with question 13, "Add to family income," valued the lowest at 1.32 . The first column indicates the rank order. The second column lists the questionnaire item and in parentheses gives its number as it appeared on the questionnaire. The third, fourth, fifth and sixth columns give the number of respondents, the mean, the standard deviation and range for each item, respectively.

Questions number 40 and 41 received the same mean score and standard deviation. They were given the same rank of 14 and listed in the order they appeared on the questionnaire.

of the 21 questionnaire items ranked in Table II, eight show a mean score $\geq 5.00$, indicating a high degree of importance as defined above. They are numbers $2,3,4,19$, 23, 24,36 , and 42 .

How the several literature goals are reflected in the questionnaire items was explained in Chapter III. In the following discussion, their importance in the literature is compared to how they were ranked for importance by the host 
TABLE II

RANK ORDER FOR IMPORTANCE OF

LITERATURE-BASED QUESTIONNAIRE ITEMS BY HOST FAMILIES Questionnaire Item

1. Children interact with guest (2)

$51 \quad 6.14 \quad 1.02 \quad 3-7$

2. Share family's lifestyle (4)

$\begin{array}{llll}68 & 5.51 & 1.26 & 2-7\end{array}$

3. Develop guest personally (19)

$\begin{array}{llll}66 & 5.35 & 1.36 & 1-7\end{array}$

4. Understand another culture (24)

$\begin{array}{llll}68 & 5.34 & 1.63 & 1-7\end{array}$

5. Show guest American values/ way of life (36)

6. Educate self (23)

$\begin{array}{llll}67 & 5.22 & 1.52 & 1-7\end{array}$

7. Interact with specific culture (3)

$67 \quad 5.13 \quad 1.81 \quad 1-6$

$\begin{array}{llll}65 & 5.11 & 1.59 & 1-7\end{array}$

8. Promote international goodwill/ peace (42)

9. Establish long-term relationship (1)

10. Change family views of cultures (34)

$\begin{array}{llll}65 & 5.08 & 1.80 & 1-7\end{array}$

$\begin{array}{llll}67 & 4.79 & 1.67 & 1-7\end{array}$

$\begin{array}{llll}65 & 4.78 & 1.10 & 1-7\end{array}$

$\begin{array}{llll}64 & 4.69 & 1.83 & 1-7\end{array}$

11. Develop family personally (18)

$\begin{array}{llll}67 & 4.64 & 1.86 & 1-7\end{array}$ development (27)

13. Get guest's perception of Americans (35)

14. Increase knowledge for human welfare (40)

14. Increase guest's knowledge for human welfare (41)

16. Develop self personally (17)

17. Help guest learn English (26)

18. Develop support for political system (37)

$\begin{array}{llll}66 & 4.48 & 1.99 & 1-7\end{array}$

$\begin{array}{llll}64 & 4.41 & 2.14 & 1-7\end{array}$

$64 \quad 4.41 \quad 2.14 \quad 1-7$

$\begin{array}{llll}66 & 4.39 & 1.73 & 1-7\end{array}$

$\begin{array}{llll}65 & 3.72 & 1.88 & 1-7\end{array}$

$\begin{array}{llll}64 & 3.53 & 2.19 & 1-7\end{array}$

$\begin{array}{llll}60 & 3.43 & 2.06 & 1-7\end{array}$

19. Sensitize guest's cultural identity (28)

20. Practice foreign language (25) $\quad \begin{array}{lllll}67 & 3.16 & 2.10 & 1-7\end{array}$

21. Aid a less developed society (43) $50 \quad 3.10 \quad 2.16 \quad 1-7$ 
families. Through this process it will be possible to determine to what extent the literature goals were important to these host families.

\section{IIE Goals}

The first set of goals examined are those of the IIE. All five were represented in the questionnaire. They are listed below in their order of frequency (or importance) as ranked by the IIE. The numbers in parentheses indicate the questionnaire items related to these particular goals:

1. To promote international understanding and good will among the peoples of the world as a contribution to peace. (42)

2. To develop friends and supporters for the United States by giving persons from other countries a better understanding of the life and culture of the United States. (36)

3. To contribute to the economic, social or political development of other countries. (43)

4. To aid in the educational or professional development of outstanding individuals. (27)

5. To advance knowledge throughout the world for the general welfare of mankind. $(40,41)$

of these five IIE goals, two that I asked about had mean scores of $\geq 5.00$. The first of these is to promote international understanding and good will among the peoples of the world as a contribution to peace. This goal was represented by question 42 (mean $=5.08, S D=1.80)$, which ranked eighth in importance.

The second IIE goal rated as important by the host families was to develop friends and supporters for the 
United states by giving persons from other countries a better understanding of the life and culture of the united states. It was reflected in question 36 (mean $=5.22, \mathrm{SD}=$ 1.521 , and was ranked fifth in importance.

The remaining three IIE goals were rated unimportant by the host respondents. Of these, to contribute to the economic, social or political development of other countries, represented by question 43 (mean $=3.10, \mathrm{SD}$ $=2.101$, was ranked $20 \mathrm{th}$, or lowest in importance. This is congruent with the results of a 1985 study on program sponsors' attitudes towards 15 goals and objectives in which this goal was also rated the lowest by those respondents (Bacheller 1985, 111).

It should be noted, however, that the wording of question 43 may have distorted the original IIE goal. It asks: How important was it for you to provide an opportunity to an individual from a less developed society who can return and contribute to the economic, social or political development of their own country? (emphasis added). It might have been best to omit the distinction, "from a less developed society". All the visitors in these particular exchange programs were from Japan, which is not a "less developed society," and for that reason the host families may not have perceived this goal as important.

Although the two remaining IIE goals were not rated $\geq 5.00$, neither was rated extremely low, either. The fourth 
goal, "To aid in the educational or professional development of outstanding individuals," as represented by question 27 , ranked $12 \mathrm{th}$ in importance (mean $=4.64, \mathrm{SD}$ $=1.86)$. This question asked: How important was it for you to aid in the educational or professional development of your guest?

That this goal was rated unimportant by the host families is an interesting difference compared to the importance it has assumed in other studies. Gullahorn and Gullahorn (1958) conclude that for students, their educational and professional development is "of paramount importance in... [their] decision to study abroad" (370). Of 607 American students they queried concerning their objectives for studying abroad, 75 percent considered this one of the three most important reasons for their participation. Abrams (1960) considers it to be one of the three general headings under which most study abroad objectives can be grouped (4).

For the host families in this study, however, their guest's educational or professional development was perceived as unimportant. This may be attributed to the fact that neither exchange program had educational or professional ambitions and, in the case of the Labo/Lex program, the visitors were very young, aged 12 and under. Within this context, furthering their guest's professional or educational development would not have been of primary importance to the host families. 
The fifth goal, "To advance knowledge throughout the world for the general welfare of mankind," was divided into two questions, numbers 40 and 41 . Question 40 was directed toward the respondent. It asked: How important was it for you to increase your intercultural knowledge for the general welfare of humanity? (mean $=4.41, S D=1.96$ ), and was ranked 14 th. Question 41 was redirected toward the experience of the guest, asking: "How important was it for you to increase your guest's intercultural knowledge for the general welfare of humanity? It rated exactly the same as question 40 (mean $=4.41, S D=2.14)$, and was also ranked 14 th.

It is difficult to say with any certainty why this goal was not given greater importance by the respondents. Bennett views it as both ambiguous and unassailable (69). In hopes of reducing this ambiguity, I rephrased it as "increasing intercultural knowledge." It is not apparent, however, that this provided greater clarity. From the value given it by the host families, it appears that Bennett's comment continues to be valid.

In sum, using a mean score $=5.00$ as the lowest possible value indicating importance, only two of the five IIE goals can be considered as relevant to the host families. They are the goals of promoting international understanding and of developing friends and supporters for the United States. The third IIE goal, to contribute to the economic, 
social or political development of other countries, was rated the lowest of all the literature-based goals. The value placed on the fourth and fifth goals, while not unimportant, indicate that they are not of high priority for the host families.

\section{NICSA Goals}

The second set of literature goals from which questions were formulated were five of six identified by Bennett (1985) in her work with the Northwest Interinstitutional Council on study Abroad (NICSA). As discussed in Chapter III, the sixth goal, to stimulate academic achievement in an environment relevant to the subject, was omitted because the exchange programs in which these respondents participated had no academic element. The five that were included are listed below. The order in which they appear does not indicate importance. The numbers in parentheses indicate the questionnaire items related to these particular goals:

1. To provide an opportunity for intensive foreign language study. $(25,26)$

2. To increase awareness of the students' role in his or her own culture. $(28,35)$

3. To achieve understanding of another culture. (2, 3,241

4. To encourage personal development. $(17,18,19)$

5. To broaden a liberal arts education. (23)

The first NICSA goal, to provide an opportunity for intensive language study, was rated $<5.00$ by the host families. It was addressed by two questions, numbers 25 
and 26. Question 26 dealt with the host's desire to help the visitor. It asked: How important was it for you to provide your guest with an opportunity for intensive language study? This was rated low (mean $=3.72, \mathrm{SD}=1.88$ ), and ranked 16 th in importance. Question 25 dealt with the respondent's own desire for language study. It asked: How important was it for you to learn or practice the language of your guest? It rated slightly lower than question 26 (mean $=3.16, S D=2.10)$ and was ranked 19 th in importance.

It is apparent that language study, either for themselves or for their guests, was of little importance for the host families. Two factors may account for this. One, the programs did not emphasize academics in any form, which could be inferred from the term "language study." While the Japanese guests may have been motivated to improve their language skills, the host families would not have viewed providing an opportunity for this as their role. Two, the host families had no familiarity with Japanese and, with visits as short as these, had little or no time to grasp even the basics of this very difficult language. Thus, language study would have held little importance for the respondents.

This low ranking is in congruence with Bennett's findings. She says, 
...it is not surprising that this was rated rather low by both NICSA students and NICSA Council members. students ranked it their fifth goal (the only lower value was to broaden a liberal arts education) and NICSA Council members rated it lowest. While struggling host families and country directors may wish it were otherwise, the current commitment of the NICSA Council seems to match the ambitions of the participants (85).

The low ratings of these host families indicate that, in spite of their "struggle", they too have little ambition for providing or receiving language study.

The second NICSA goal, to increase awareness of the students' role in his or her own culture, was also rated low. This was represented by two questions, numbers 28 and 35, to address the issue of cultural self-awareness in both the guest and the respondent. Question 28 dealt with the host family helping their guest become more self-aware. It asked: How important was it for you to sensitize your guest to his/her own cultural identity? (mean $=3.43, \mathrm{SD}=2.06$ ), and was ranked 18 th in importance.

This goal was expanded to include the development of the host family member's own cultural self-awareness as well as the visitor's. Question 35 asked: How important was it for you to learn about Americans from the perspective of a person from another culture? (mean $=4.48, \mathrm{SD}=1.99)$. Ranked 13th in importance, the goal of developing their own cultural self-awareness was noticeably more important to the host families than developing their guest's. 
These results are also congruent with Bennett's study. As she points out, cultural self-awareness is heavily stressed in the intercultural training literature but virtually ignored outside the field of intercultural communication (87). In the NICSA study, this goal rated third among the students and fifth by the NICSA Council. Bennett attributes this to the younger generation feeling more comfortable with terms like "awareness" while the older Council members may have been unfamiliar with the term (87-8). The average age of the host families places them at least in middle age, comparable to that of the council members. The programs they participated in were quite informal and provided no training through which they might have been introduced to important intercultural communication concepts. That they might also be unfamiliar with the term "cultural self-awareness" is a distinct possibility.

of the eight questions rated $\geq 5.00$, three represented the third NICSA goal of achieving understanding of another culture. The first of these was question 2 (mean $=6.14$, SD $=1.02$ ) which ranked first in order of importance. The second was question 24 (mean $=5.34, \mathrm{SD}=1.63$ ) with a rank order of fourth in importance. The third question was number 3 (mean $=5.11, S D=1.59)$ which had a rank order of seventh in importance. 
These findings corroborate Bennett's findings, in which both the students and the NICSA Council rated understanding of other cultures as their primary goal (73-75). They also support Gullahorn and Gullahorn's findings in their study cited above. The 607 students they queried were participants in a study abroad program in France. The authors comment:

In a general way every American interviewed expressed interest in gaining understanding of French culture ....For 67 per cent it had been a primary influence in their decision to go abroad (371).

The fourth NICSA goal, to encourage personal development, was also represented by multiple questionnaire items. This is a goal that can be perceived from three perspectives: That of the host family member's own development; of the family member's expectations for other members of the family; and the effect the host family might want to have on their guest. Questions 17, 18, and 19 reflect these different perspectives, respectively. Question 17 (mean $=4.39, \mathrm{SD}=1.73)$, ranked $15 \mathrm{th}$ in importance. Question 18 was rated slightly higher (mean $=4.69, \mathrm{SD}=$ $1.83)$, and ranked 11 th. Question 19 was the only one of the three to rate $\geq 5.00$ (mean $=5.35, \mathrm{SD}=1.36)$, and it was ranked third in importance. These results indicate that the personal development of other family members was more important to the respondents than their own. But of greatest importance was the personal development of their foreign guest. 
Why this is the case is unclear. Perhaps they view their participation in an altruistic manner. It is particularly puzzling in light of several comments made by respondents that their participation had been a growth experience, either for themselves or for other family members, while no comments were made regarding the effect on their guests.

In Bennett's study, the students rated personal development second while the Council members rated it as third in importance (86). The difference was not statistically significant, and Bennett concludes that while the rank order is different, students and Council members share the same goals (75-8). That the host families did not rank any of these goals extremely low, in conjunction with their additional comments, indicates they also share this goal, but in an order of their own.

The last NICSA goal, to broaden a liberal arts education, was addressed in only the most general of terms by this survey. Question number 23 asked: How important was it for you to have an educational experience through hosting someone from another culture?" (mean $=5.13, \mathrm{SD}=1.81$ ). It ranked sixth among the 21 questionnaire items. It was surprising that it ranked so high, given the lack of emphasis upon formal education in either program. But in their written comments, many expressed a desire to learn about another culture, which definitely qualifies as an 
educational experience. Education is more than pure academics and it is possible that that is how the respondents chose to understand this question.

The students in the NICSA study ranked broadening education last in importance, and the council ranked it second (79). Again, the difference was not statistically significant. The host families responded in a manner similar to the Council. But no matter how the students, Council members and host families might differ in their ranking of the goals, they are in consensus about the importance of this one.

Table III shows the order of importance in which 181 students from 14 college campuses, 14 NICSA Council members and 69 Tillamook County host family members rated the five NICSA goals evaluated in this study. Bennett's subjects were asked to rate the goal on a 1-7 Likert-type scale, ranging from "not at all important" to "very important." Because the students were from three pools of participants in England, France and Germany for either the spring or Winter quarters, she provided a composite mean for their responses $(71-4)$.

In the survey instrument developed for the host family study, four of the five goals were represented by more than one questionnaire item. The goal of broadening a liberal arts education was represented by only one item (mean = $5.13, \mathrm{SD}=1.81)$. A grand mean for the other four items was 


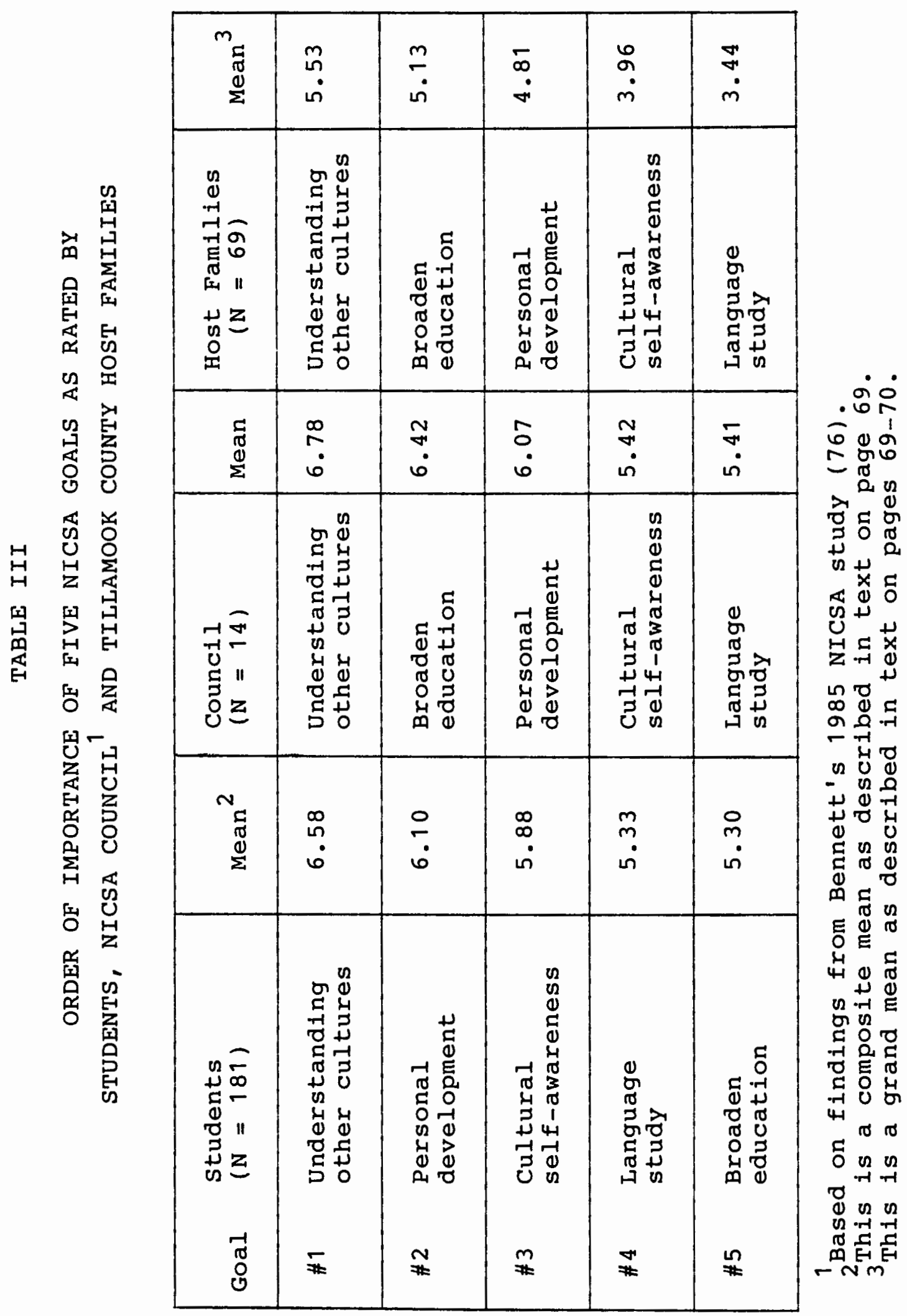


calculated by adding together the mean score of all items related to each and dividing by the number of items added. The calculations were based on the following data:

1. Understanding other cultures

$\begin{aligned} \text { Question 2: } & \text { Mean }=6.14, \quad \mathrm{SD}=1.02 \\ \text { Question 3: Mean } & =5.11, \mathrm{SD}=1.59 \\ \text { Question 24: Mean } & =\underline{5.34}, \mathrm{SD}=1.63 \\ \text { Total } & =16.59 \\ \text { Divided by } 3 & =\text { Grand mean }=5.53\end{aligned}$

2. Personal development

$\begin{aligned} \text { Question 17: Mean } & =4.39, \quad \mathrm{SD}=1.73 \\ \text { Question 18: Mean } & =4.69, \mathrm{SD}=1.83 \\ \text { Question 19: } & \text { Mean }=\underline{5.35}, \mathrm{SD}=1.63 \\ \text { Total } & =16.43\end{aligned}$

Divided by $3=$ Grand mean $=\underline{4.81}$

3. Cultural self-awareness

Question 28: Mean $=3.43, \mathrm{SD}=2.06$

Question 35: Mean $=4.48, S D=1.99$

Total $=7.91$

Divided by $2=$ Grand mean $=\underline{3.96}$

4. Language study

$$
\begin{aligned}
\text { Question 25: Mean } & =3.16, \mathrm{SD}=2.10 \\
\text { Question 26: Mean } & =3.72, \mathrm{SD}=1.68 \\
\text { Total } & =6.88 \\
\text { Divided by } 2 & =\text { Grand mean }=\underline{3.44}
\end{aligned}
$$

The goal of understanding another culture consistently was rated first by the students, Council members and host families. The Council and host families continued to rate the remaining four goals in the same order, while the students indicated a different set of priorities. Although the host families had the same priorities as the Council, it it is important to remember they did not rate cultural 
self-awareness and language study high enough for these goals to be evaluated as relevant to their experience.

To summarize, with a mean score $\geq 5.00$ indicating importance, the data show that two of Bennett's NICSA goals, understanding another culture and broadening a liberal arts education, were perceived as important by the host families. The goal of encouraging personal development did not, on the whole, rate high enough to be regarded as important. It was represented by three questions that addressed the respondent's, other family members' and the guest's personal development.

Only one of these three items, development of the guest, rated high enough to be considered important. When averaging the individual mean scores of the three questions together, this goal falls below the established level of importance. The last two goals, developing cultural selfawareness and providing an opportunity for language study, also rated low in importance to the respondents.

\section{Other Literature-Based Goals}

The last four literature-based goals included in this survey were based on the research of King and Huff (1985), Van de Water (1970) and Lowe, et al. (1984). They are listed below, with the research source indicated in parentheses: 
1. To establish a long-term relationship (Lowe, et al.)

2. To share family's lifestyle with someone from another culture (King \& Huff)

3. To change family views of cultures (Lowe, et al.)

4. To promote political ideas in which one believes (Van de water)

These four goals were represented by questions 1, 4, 34 , and 37, respectively. of the four, only the goal of sharing the family's lifestyle is rated $\geq 5.00$ in importance. This goal was expressed by question 4 (mean $=5.51$, $\mathrm{SD}=1.26)$, which ranked second in importance. These results corroborate King and Huff's assertion that there are two basic elements for hosting a foreign student, sharing your lifestyle and providing a helping hand.

Question 1, which asked: How important was it for you to establish a long-term relationship with someone from another culture? was rated $<5.00$ (mean $=4.79, \mathrm{SD}=1.67)$, and ranked ninth in order of importance. This is not an extremely low evaluation, which indicates this goal has some importance for the host families. The lower rating may be a result of asking about establishing "long-term relationships," rather than simply asking about friendship. Several respondents, for example, commented that they enjoyed the friendship they shared with their guest but felt it was likely to be temporary. Although this goal was not valued at a high enough level to be considered relevant to the host families, it also should not be completely disregarded. 
The low rating of question 1 fails to support the findings of Lowe, et al. In their study of the Council of International Programs for Youth Leaders (CIP), they reported that the families viewed the development of long-term friendships as a notable strength of the CIP program. While the authors did not establish whether the host families had this goal before they began their hosting experience, they state, "Host families expect to establish friendships and complain when there was a lack of sharing by the participant" (57). The ratings of this goal by the host families indicate they did not share the expectations of those who participated in the CIP program.

Question number 34 asked: How important was it for you to provide members of your family with the opportunity to change their views of people from other cultures? This was rated $<5.00$ (mean $=4.78, \mathrm{SD}=1.10)$, and was ranked 10 th in order of importance. This also is not an extremely low evaluation, which means it, too, can be regarded as having some relevance for the host families.

The goal of changing family views, which this question represented, was also suggested by Lowe, et al.'s CIP study. The authors report:

CIP host families strongly agree that they have increased their understanding of values and issues. ...Families believe that CIP has helped them understand both their own and other countries' cultures. Nineteen families said that a strength of the program was the cultural understanding that their children developed. As a result of the understanding achieved 
through intercultural contact, the host families reported that both they and their families have changed or expanded their perceptions about the world (57).

This response was a result of intercultural contact, however, not a goal. Using the CIP findings to formulate a goal was an attempt in this study to determine whether host families consciously try to change their stereotypes and perceptions of the world. The rating for question 34 indicates they do not to the extent claimed by Lowe and his fellow researchers.

The final literature-based question examined is number 37, which was based upon Van de Water's motivational item, they want to promote political ideas in which they believe. The question asked: How important was it for you to develop friends and supporters for the American way of life by giving persons from other countries a better understanding of our political system? This was rated low (mean $=3.53, \mathrm{SD}=2.19)$, and ranked 17 th in importance. This low ranking concurs with Van de Water's findings. Out of nine motivational item he used, this is one of three that were rated low in importance by his host families. It was also perceived by the host families' guests as being of little importance to the hosts $(64)$.

To conclude, then, of these four remaining literaturebased goals, only one achieved a rating of importance. This was the goal of sharing your lifestyle with a person from another country, based on the research of King and Huff. 
Summary of Literature-Based Goals Rated As Important By The Host Families

Fourteen established literature goals were represented in this survey. Five of these achieved a rating of $\geq 5.00$ in importance and can be considered relevant to the host families. In rank order, they are:

1. To achieve understanding of another culture. (Questions 2, 3, 24)

2. To share your lifestyle with a person from another country. (Question 4)

3. To develop friends and supporters for the United States by giving persons from other countries a better understanding of the life and culture of the United States. (Question 36)

4. To broaden a liberal arts education (Question 23)

5. To promote international understanding and good will among the peoples of the world as a contribution to peace. (Question 42)

How the host families evaluated their experience in terms of these goals will be discussed later in this chapter. First, however, non-literature-based goals that were rated high in importance also need to be identified.

Ratings of Non-Literature-Based Goals

Twenty-two of the 43 questionnaire items were based on non-literature sources. Table IV presents the host family ratings for each of these items. The table is in the same format as Table I. The columns show the complete item, the mean, the standard deviation and the range for that particular item. 
TABLE IV

MEAN RATINGS FOR IMPORTANCE OF

NON-LITERATURE-BASED GOALS BY HOST FAMILIES

Questionnaire Item

and Item Number

N Mean SD Range

5. Bring family closer

$\begin{array}{llll}67 & 4.28 & 1.90 & 1-7\end{array}$

6. Strengthen marriage

$\begin{array}{llll}46 & 2.00 & 1.70 & 1-7\end{array}$

7. Experience parenting

$\begin{array}{llll}3 & 2.67 & 2.89 & 1-6\end{array}$

8. Experience boy or girl

$\begin{array}{llll}11 & 2.45 & .97 & 1-7\end{array}$

in family

9. Have child live in home again

$12 \quad 3.33 \quad 2.15 \quad 1-7$

10. Companionship for own child

$\begin{array}{llll}41 & 2.36 & 1.76 & 1-7\end{array}$

11. Please own children/parents

12. Positive role model for own children

13. Add to family income

14. Provide household help

15. Add childcare for own children

16. Establish travel contact

20. Relive own exchange experience

$\begin{array}{llll}55 & 3.44 & 2.18 & 1-7\end{array}$

$\begin{array}{llll}48 & 3.12 & 2.10 & 1-7\end{array}$

$\begin{array}{llll}63 & 1.32 & .93 & 1-7\end{array}$

$\begin{array}{llll}62 & 1.40 & 1.03 & 1-6\end{array}$

$59 \quad 1.19 \quad .90 \quad 1-5$

$\begin{array}{llll}67 & 3.15 & 1.97 & 1-7\end{array}$

$\begin{array}{llll}26 & 2.96 & 2.25 & 1-7\end{array}$

21. Have fun

$\begin{array}{llll}62 & 5.71 & 1.37 & 1-7\end{array}$

22. Satisfy curiosity about hosting

$\begin{array}{llll}60 & 3.98 & 1.79 & 1-7\end{array}$

29. Learn about own heritage

30. Share community hosting

$\begin{array}{llll}42 & 1.86 & 1.57 & 1-7\end{array}$

$\begin{array}{llll}66 & 4.47 & 1.89 & 1-7\end{array}$

31. Help program coordinator

$\begin{array}{llll}51 & 4.18 & 1.76 & 1-7\end{array}$

32. Gain recognition in community

$\begin{array}{llll}62 & 2.31 & 1.72 & 1-7\end{array}$

33. Risk unpredictable challenge

$\begin{array}{llll}65 & 3.62 & 1.82 & 1-7\end{array}$

38. Practice religious principles

65

$3.78 \quad 2.40 \quad 1-7$

39. Have personal intercultural

63

$5.00 \quad 1.88 \quad 1-7$
experience 
Table $V$ indicates the rank order of these items. It begins with question 21, "Have fun," valued the highest at 5.71, and ends with "Add childcare for own children," valued the lowest at 1.32. As in Table II, the columns indicate the rank order, the complete item with the number of the item as it appeared in the questionnaire in parentheses, the number of respondents, the mean, the standard deviation and the range for each item.

of the 22 questionnaire items ranked in Table $V$, only two show a mean score $\geq 5.00$, indicating a high degree of importance. The first is question number 21, which asked: How important was it for you to have fun? It was ranked the highest of all 43 questions (mean $=5.71, S D=$ 1.37). It is a rather fundamental goal which was mentioned by all the volunteer coordinators I interviewed prior to the survey. Having fun was also repeatedly mentioned in the questionnaire where it was asked if there were any additional factors the host families regarded as relevant to their volunteering as a host family.

The second is question number 39, which asked: How important was it for you to have a personal intercultural experience? $($ mean $=5.00, S D=1.88)$. It ranked second of the 22 non-literature-based goals. When ranked with question 21 and the eight literature-based goals that were rated high in importance, this goal ranked 10 th of 10 . 
TABLE V

RANK ORDER FOR IMPORTANCE OF

NON-LITERATURE-BASED ITEMS BY HOST FAMILIES

Questionnaire Item

Rank and Item Number

1. Have fun (21)

N Mean SD Range

2. Have personal intercultural experience (39)

3. Share community hosting (30)

5. Bring family closer (5)

$\begin{array}{llll}62 & 5.71 & 1.37 & 1-7\end{array}$

6. Help program coordinator (31)

$\begin{array}{llll}63 & 5.00 & 1.88 & 1-7\end{array}$

7. Satisfy curiosity about hosting (22)

8. Practice religious principles (38)

9. Risk unpredictable challenge (33)

10. Please own children/ parents (11)

11. Have child live in home again (9)

12. Establish travel contact (16)

$\begin{array}{llll}66 & 4.47 & 1.89 & 1-7\end{array}$

$\begin{array}{llll}67 & 4.28 & 1.90 & 1-7\end{array}$

$\begin{array}{llll}51 & 4.18 & 1.76 & 1-7\end{array}$

$\begin{array}{llll}60 & 3.98 & 1.79 & 1-7\end{array}$

$\begin{array}{llll}65 & 3.78 & 2.40 & 1-7\end{array}$

$\begin{array}{llll}65 & 3.62 & 1.82 & 1-7\end{array}$

$\begin{array}{llll}55 & 3.44 & 2.18 & 1-7\end{array}$

$\begin{array}{llll}12 & 3.33 & 2.15 & 1-7\end{array}$

13. Positive role model for own children (12)

14. Relive own exchange experience (20)

15. Experience parenting (7)

$\begin{array}{llll}67 & 3.15 & 1.97 & 1-7\end{array}$

$\begin{array}{llll}48 & 3.12 & 2.10 & 1-7\end{array}$

$\begin{array}{llll}26 & 2.96 & 2.25 & 1-7\end{array}$

16. Experience boy/girl in family (8)

17. Companionship for own child (10)

$\begin{array}{llll}41 & 2.36 & 1.76 & 1-7\end{array}$

18. Gain recognition in community (32)

$\begin{array}{llll}62 & 2.31 & 1.72 & 1-6\end{array}$

19. Strengthen marriage (6)

$\begin{array}{llll}46 & 2.00 & 1.70 & 1-7\end{array}$

20. Learn about own heritage (29)

$\begin{array}{llll}42 & 1.86 & 1.57 & 1-7\end{array}$

21. Provide household help (14)

$\begin{array}{llll}62 & 1.40 & 1.03 & 1-6\end{array}$

22. Add to family income (13)

$\begin{array}{llll}63 & 1.32 & .93 & 1-5\end{array}$

23. Add childcare for own

$\begin{array}{llll}59 & 1.19 \quad .90 \quad 1-5\end{array}$ children (15) 
None of the remaining 20 questionnaire items based on non-literature sources were rated high in importance by the host families.

It is apparent from this analysis that the host families evaluated the literature-based goals as having far greater importance than the goals from other sources. How they evaluated their experience in terms of achieving the goals they perceived as relevant comprises the final aspect of the data analysis.

HOST FAMILY RATINGS OF GOALS FOR ACHIEVEMENT

In addition to rating the goals for importance, the host families were asked to rate to what extent they achieved each goal. The data show that the same eight literature-based items rated high in importance were also rated $\geq 5.00$ for achievement. None of the items rated $<5.00$ in importance received a rating of $\geq 5.00$ for achievement.

The rank order of these eight items is different for achievement than importance, however. Table VI shows that order. The format is the same as for the other tables. (Table $X$ in Appendix $C$ reports the mean ratings for achievement for all 21 literature-based items. So that a comparison can be made between importance and achievement, ratings for both are included for each item.) 
TABLE VI

RANK ORDER OF LITERATURE-BASED GOALS RATED $\geq 5.00$ FOR ACHIEVEMENT BY HOST FAMILIES

Questionnaire Item

and Item Number

2. Children interact with guest

4. Share family's lifestyle

24. Understand another culture

36. Show guest American values/ way of life

23. Educate self

19. Develop guest personally

3. Interact with specific culture

42. Promote international goodwill/ peace
N Mean SD Rng

$51 \quad 5.84 \quad 1.16 \quad 3-7$

$\begin{array}{llll}68 & 5.56 & 1.30 & 2-7\end{array}$

$\begin{array}{llll}66 & 5.55 & 1.31 & 1-7\end{array}$

$67 \quad 5.46 \quad 1.41 \quad 2-7$

$\begin{array}{llll}65 & 5.34 & 1.63 & 1-7\end{array}$

$\begin{array}{llll}65 & 5.32 & 1.31 & 2-7\end{array}$

$\begin{array}{llll}65 & 5.03 & 1.40 & 1-7\end{array}$

$\begin{array}{llll}65 & 5.00 & 1.70 & 1-7\end{array}$

The data show that three of the non-literature-based goals rated $\geq 5.00$ for achievement. Table VII shows the rank order of the three items rated $\geq 5.00$ for achievement. Its format is also the same as for the other tables. (Table $X I$ in Appendix $C$ reports the mean ratings for achievement for all 22 non-literature-based goals. Again, importance and achievement are compared.)

\section{TABLE VII}

RANK ORDER OF NON-IITERATURE-BASED GOALS RATED

$\geq 5.00$ FOR ACHIEVEMENT BY HOST FAMIIIES

Questionnaire Item

and Item Number

$\mathrm{N}$ Mean SD Rng

21. To have fun

$\begin{array}{llll}62 & 5.73 & 1.47 & 1-7\end{array}$

22. To satisfy curiosity about hosting

$\begin{array}{llll}60 & 5.00 & 1.84 & 1-7\end{array}$

39. To have a personal intercultural

$63 \quad 5.00 \quad 1.68 \quad 1-7$ experience 
One of the non-literature-based items was rated $<5.00$ for importance but $\geq 5.00$ for achievement. This was question 22. Given the general pattern of consistent rating between importance and achievement of all the other goals, however, this is probably a statistical anomaly.

of the eight literature-based and two non-literaturebased items that were rated $\geq 5.00$ in importance, all were also rated $\geq 5.00$ for achievement. All but one of the remaining 33 items were rated $<5.00$ for achievement. In other words, there was virtually no discrepancy in the ratings for importance and achievement for all 43 questionnaire items. This may indicate that the respondents did not differentiate between importance and achievement which may have been due to a flaw in the design of the survey instrument. This will be discussed at greater length in the final chapter under limitations of the study.

Aside from the possibility of a design flaw, the data indicate that the goals the host families perceived as important were achieved and those they perceived as unimportant were not. Perhaps the families created a self-fulfilling prophecy and achieved only what they expected. Or perhaps these host families are realistic about what can be achieved from a short intercultural exchange. Almost two-thirds of the participants were repeat host families. Prior experience may have taught them that certain goals are unattainable or unimportant. For them, hosting may be an 
enjoyable way of interacting with an individual from another culture on a personal level, an experience from which they expect little more than having fun and gaining some knowledge about another culture.

In terms of this study's fourth research question regarding how host families evaluate their homestay experience, the data show that they evaluate it as successful and satisfying. Goals rated as important were achieved and those they perceived as unimportant were not.

Many of the written comments from the participants reinforce this conclusion. They are enthusiastic and pleased with their experience. One host mother commented, "I enjoyed the time with the student--added to life." Another said she enjoyed it "because it was fun and we all grew a little and we made new friends." A host father who had hosted before stated that it is "always a special experience. An opportunity to share life." And a host sister said what so many had stated as I collected their questionnaires. She wrote:

I got to know and enjoy the different cultures of the people around the world. This was the best experience I've ever had and I recommend it to everybody to participate.

These comments, and the fact that almost all the respondents said they would host again if the opportunity presented itself, suggest that the host families evaluated their experience positively and that it met their expectations. 


\section{SUMMARY OF RESULTS}

The results of this study show that the host family respondents perceived most of the goals established in the literature of international exchange as not relevant to their experience. In addition, several goals based on sources other than the literature also were perceived as not relevant. Goals perceived as important were also rated high for achievement, and goals perceived as unimportant were rated low for achievement, with only one discrepancy in this pattern.

Fourteen literature-based and 22 non-literature-based goals were represented by 43 questions in a survey questionnaire completed by 69 host family respondents. Table VIII summarizes seven goals the respondents rated high in importance $($ mean scores $=$ or $>5.00)$. Five are from the literature and two from other sources. They are listed in rank order, beginning with the non-literature-based goal of having fun, which ranked the highest of all seven goals.

Understanding of another culture was ranked first among the literature-based goals and second overall. This is congruent with results from other studies evaluating objectives of sojourners and program sponsors in which this was ranked as the most important goal (Bennett 1985; Bacheller 1985). 


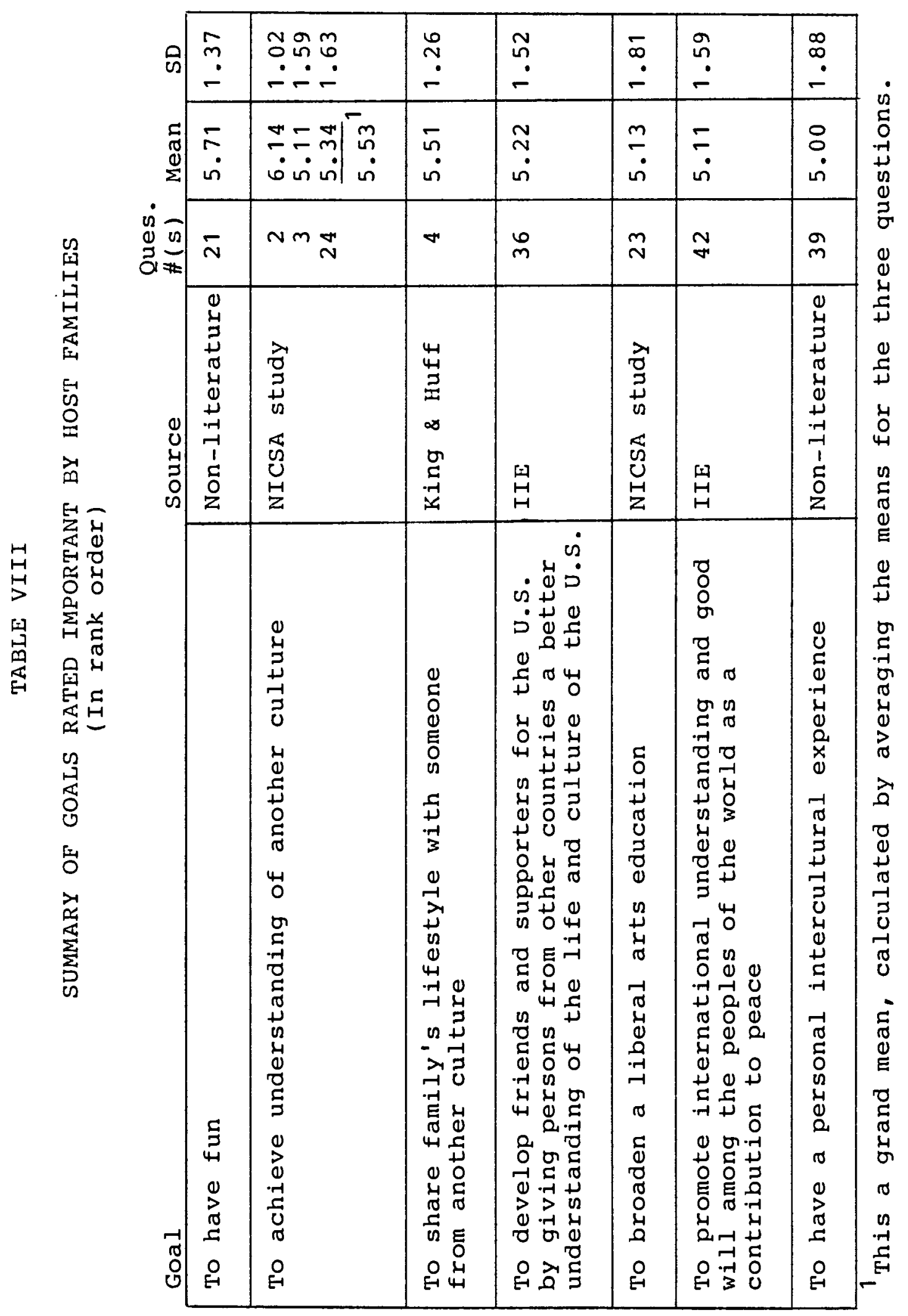


King and Huff, authors of the Host Family Survival Kit: A Guide for American Host Families, consider sharing the family's lifestyle as one of two basic elements in hosting. This goal was ranked third highest in importance by the respondents, indicating congruence with the literature.

The IIE goal of developing friends and supporters for the United States by giving persons from other countries a better understanding of the life and culture of the United States ranked fourth. This shows that the host families regard international understanding as a reciprocal process, as important for their guests to achieve as it is for them.

The host families in this study evaluated broadening a liberal arts education as fifth highest in importance. This was an unexpected result since education was not emphasized in either of the exchange programs in which the respondents participated. However, it is assumed they interpreted the goal in the broadest sense of learning, not as formal education.

The final literature-based goal rated high in importance was to promote international understanding and good will as a contribution to peace. In 1955, the IIE ranked this first among their five goals of international exchange. Three decades later it is ranked sixth of the seven goals found important by the host family respondents. The NICSA goal of understanding another culture, ranked 
highest of the literature-based goals, seems less global and therefore more attainable. For this reason, perhaps, it superseded the more grandiose IIE goal in the respondents' perception of relevance.

The last of the seven important goals, to have a personal intercultural experience, is one of two from sources other than the literature. It was suggested by several experienced host families who said that the desire to interact with someone from another culture often is satisfied by hosting. It can also be interpreted as an extension of wanting to understand another culture, reinforcing the primacy of that goal.

Table IX summarizes the nine literature-based goals that were not perceived as relevant by the host families. They are listed in rank order, beginning with encouraging personal development. This goal was not evaluated as important to the host families because only one of the three questionnaire items addressing it rated high in importance. Taking the three items as an aggregate whole, I did not think this goal achieved an acceptable level of importance. The ratings of the next two goals, establishing a long-term relationship and changing their views of people from other cultures, were based on Lowe, et al.'s study of CIP host family attitudes. In that study, the authors reported these as positive affects resulting from the hosting experience, but it was not established whether the 


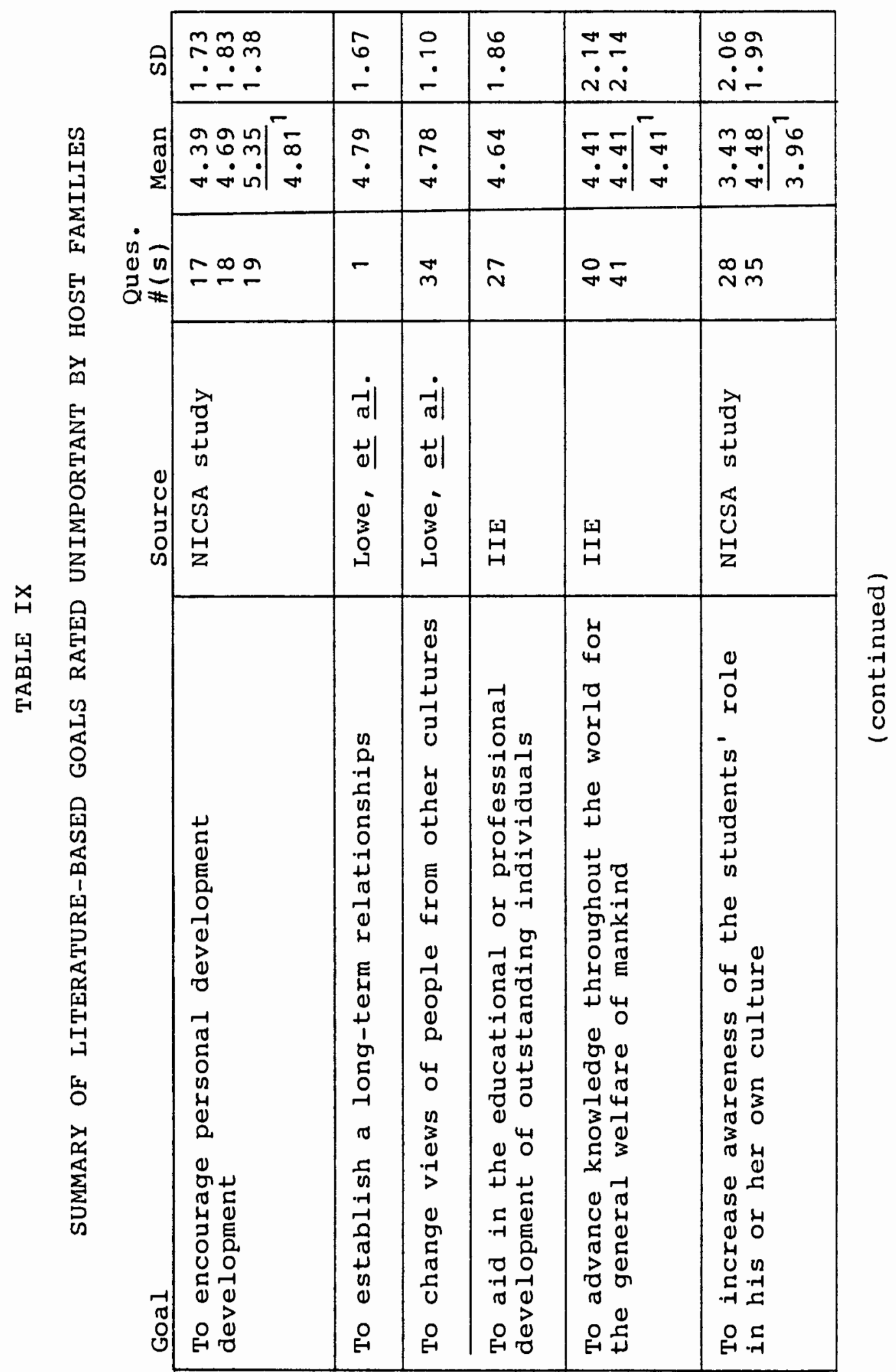




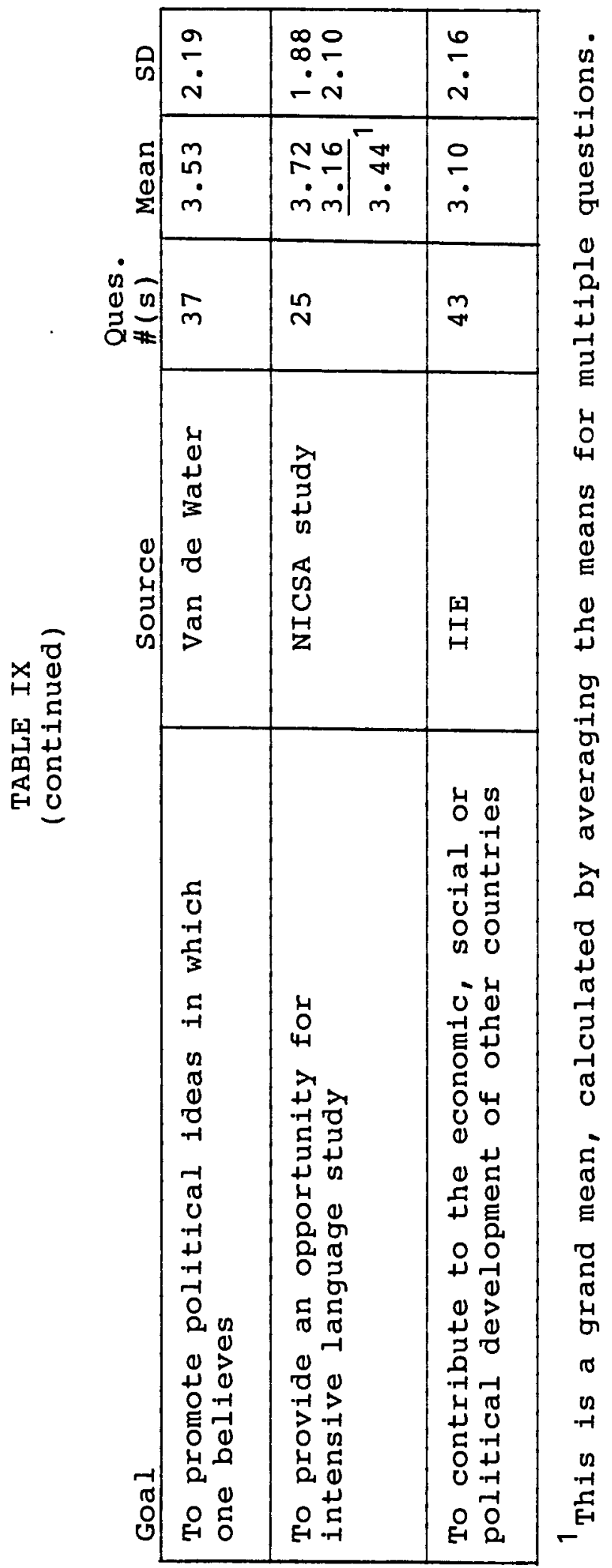


respondents had these objectives in mind before volunteering to host. The lower ratings given to these goals by the host families in the present study indicate they are not as important as Lowe, et al. assert.

The three IIE goals, 1 ) to aid in the educational or professional development of outstanding individuals, 2) to advance knowledge throughout the world for the general welfare of mankind, and 3) to contribute to the economic, social or political development of other countries, were all rated as less than important. This is congruent with the results of Bacheller's 1985 study on program sponsors' attitudes towards the IIE goals in which these three were rated not at all important (111). As he says,

A few comments written in by survey participants on the 1955 goals included: "You've got to be kidding," "These are so global, one feels silly circling a number", and "aw, come on". The low ratings coupled with comments such as these perhaps indicate that these goals reflect the ideals of a bygone era, and that priorities of program directors have changed some in thirty years $(110)$.

It may be, as Bacheller suggests, that things have changed in 30 years, and the IIE goals are no longer as relevant as they were in 1955.

The low rating given to the NICSA goal of increasing awareness of the students' role in his or her culture indicates that the host families are not familiar with the concept of cultural self-awareness. However, this is not 
surprising, given the general unfamiliarity with this concept outside the field of intercultural communication. The respondents gave a low rating to the goal of promoting political ideas in which one believes, supporting Van de Water's findings in his 1970 study that included an evaluation of host family attitudes. It is not a particularly enlightened goal, and that it was rated low speaks highly of the value the host families placed on achieving international understanding.

The ratings of the last literature-based goal, to provide an opportunity for intensive language study, were quite low. This, however, was not inconsistent with how the same goal was rated by the students and NICSA Council in Bennett's study.

This concludes the discussion of the results of the study. Implications, application and limitations of the findings are addressed in the following chapter. 
CHAPTER V

IMPLICATIONS AND LIMITATIONS OF THE STUDY

The results of the data analysis indicate that the host families' goal objectives are fewer than those expressed in the literature of international exchange. They have a general desire to increase international understanding, be it on a global basis as a contribution to world peace or on the more limited one of understanding another culture. That hosting might be an experience which contributes to their own or their family's personal development, however, or that they might change some of their views about people from other cultures does not fall within the scope of their expectations. Their ultimate goal is not, as Bochner suggests, "to free the minds of the people from their ethnocentric and monocultural shackles" (1979, as quoted in Bennett 1985).

This is not to deny the sincerity of the respondents who volunteered as host families. Rather, these findings can be interpreted in two ways. First, the families may not be reaching the full potential offered by intercultural contact. They achieve only those goals they expect to meet and overlook others they perceive as irrelevant. Or, second, the host families may be achieving all that inter- 
national exchange has to offer, and the goals they perceive as irrelevant are, in fact, outdated and unimportant.

Whichever is the case, reconciling this difference between theory and practice is an issue that has implications for the development of effective homestay programs and training programs for host volunteers. At present, exchange programs, including the orientation and training aspects, are developed from the established goals of international exchange. But the results of this study indicate that most of these are not perceived as relevant by the host families. Sponsors and trainers, therefore, need to take into consideration that the goals they regard as important and therefore emphasize may not be of interest to their audience.

Agreement on objectives is important for creating an effective and successful exchange program. The results of this study can be used in two ways to address this issue. By performing their own evaluation of the 14 literature goals and the two non-literature goals rated important, program sponsors can then determine which are important for their own exchange program. Once they have determined what their goals are, they can develop a survey instrument similar to that developed for this project, to be completed by their host families before the exchange visit begins. Through this process, program sponsors can evaluate early the extent to which they and their host families agree or disagree on program objectives. 
Those goals which sponsors view as important that are not shared by the host families can be addressed through training programs that "raise" the participants' awareness of unfamiliar intercultural communication concepts. At the same time, trainers can provide participants with guidance for achieving those goals the host families already perceive as important. In this context, training acts as a form of bridge-building between program sponsors and host families.

Trainers can also utilize a modified version of the survey instrument developed for this study in their training programs to better understand their audience's expectations. This is important because, as Bennett states,

[e]ven if a trainer can only minimally assess these goals informally at the beginning of a brief program, recognition of the audience's needs is a minimal prerequisite to a successful multidimensional training program (204).

If training were to continue throughout the homestay visit, participants could be surveyed again to evaluate the level to which they are achieving their self-identified goals and to see if any goals they evaluated as unimportant have assumed greater importance. A final survey could be taken at the end of the exchange visit, the results of which would be compared to the participants' earliest responses in order to evaluate what effect, if any, training may have had.

As with any type of survey research there were some limitations in this project. Some of them stemmed from flaws in the survey instrument. A possible distortion in 
meaning caused by the inappropriate wording of question 43 has already been discussed in Chapter IV. A second problem relates to arranging the questionnaire items into topical subsections to avoid fatiguing the respondents and maintaining their interest. Applying categorical labels to the subsections creates a potential for respondent bias. For example, respondents may have been put off by a category that labeled their guest as a "resource." Or a category dealing with "family issues" might seem inherently less important than one that addresses the grander issue of expressing one's philosophy of life. The effect of this subsectioning should be checked by testing two forms of the questionnaire, one with subsections and one without. It may be that my assumption about questionnaire fatigue justifying subsections was unwarranted.

A question is raised by the low correlation between questionnaire items 17, 18 and 19, which addressed the goal of personal development in the respondent, other family members, and the visiting guest, respectively. The low correlation may indicate two things. One, the questions were not measuring what they were designed to measure, although on the face they seem to be doing just that. A second alternative is that the construct of personal development may not be a unitary concept.

Another flaw may be that respondents failed to discriminate between importance and achievement when answering 
Parts $A$ and $B$ as presented in the questionnaire. It is possible this could be remedied by asking for evaluation of each goal first (Part $B$ ), followed by an evaluation of its importance (Part A). A better solution to the problem, however, would be to design such a survey as a two-part, longitudinal study. Before their visitor arrived, host family members would be surveyed as to the importance of each particular goal. Within a few weeks of their guest's departure, while their impressions are still fresh, a secona survey would be conducted to evaluate the extent to which they felt each goal was achieved. Preferably, this would involve in-depth interviews with at least a sample of the respondents to ascertain how well they understood the questions. The two evaluations could then be analyzed and compared for agreement or discrepancy between the two ratings for each item.

A final limitation has to do with the respondents themselves. Although they were typical of most host families, most of them lived in the same community, allowing for little socio-cultural diversity. They were not chosen at random, and therefore their responses may reflect only the cultural milieu of Tillamook county rather than host families in general. Furthermore, they were a rather small, homogeneous population with a high percentage of prior hosting experience. A larger, more diverse and/or less experienced population might have produced different data. 
However, a second study using the same survey instrument was conducted concurrently with this one as part of a yet unfinished PSU master's thesis project (Oehlschlaeger 1989). The purpose of that study was to explore differences in goal importance and achievement between 64 trained and untrained host family members living in an urban environment. The researcher's results, as reported to me in conversation, are almost identical to mine, with the exception that her subjects rated two additional non-literature goals high in importance. By increasing the number of subjects surveyed with the same questionnaire, her study mitigates some of the limits imposed by a small sample size. It provides for greater socio-cultural diversity in the survey population by evaluating urban as well as rural host volunteers. That her results are similar to those found in this project also makes it possible to draw some initial conclusions about host families in general.

\section{CONCLUSION}

It was my intention when $I$ began this project to provide some insight into the difference between theory and practice in international exchange. The literature makes certain claims for the value of cross-cultural contact. I wanted to know if those individuals who act as hosts to foreign visitors agree with the professionals in the field. 
I learned that the host families have different priorities than those of program sponsors or visiting guests. They are motivated by a desire to understand other cultures, a commitment to world peace, and above all, to having fun. Other goals of equal importance they tend to overlook.

This project has provided a systematic description of the host family experience. The value of this study is that we now have a cohesive list of goals by which we can evaluate the host family component of exchange programs. We also have a tangible resource that can be used both to identify host family expectations and to evaluate to what extent these are achieved. A survey instrument has been developed which, with some modifications, can be put to effective use in training programs designed to address all the goals of international exchange.

It is my hope that this project has provided some insight into the host family role in cross-cultural contact and advanced the field of international exchange. By understanding what host family members expect from their experience, better homestay exchange programs can be developed. If this helps to achieve the international understanding that program sponsors, sojourners and host family members alike rate as first in importance, then I will feel I have made a small contribution to world peace. 


\section{REFERENCES}

Abrams, Irwin. (1960). Study abroad: New dimensions in higher education, $\# 6$. Washington, DC: U.S. Government Printing office.

AFS International/Intercultural Programs. (1987). AFS program guide 87/88. New York, NY.

Amir, Yahuda. (1969). Contact hypothesis in ethnic relations. Psychological Bulletin, 71, 319-42.

Amir, Yahuda, \& Garti, Chana. (1977, Summer). Situational and attitudinal change following ethnic contact. International Journal of Intercultural Relations, Vol. 1, No. 2, 58-75.

Argyle, Michael. (1982). Intercultural communication. In Bochner, stephen (Ed.), Cultures in contact: Studies in cross-cultural contact, 61-79. Oxford: Pergamon Press.

Babbie, Earl R. (1973). Survey research methods. Belmont, CA: Wadsworth Publishing Co., Inc.

Babbie, Earl R. (1986). The practice of social research. Belmont, CA: Vadsworth Publishing Co., Inc.

Bacheller IV, Thomas T. (1985). An assessment of the incorporation of established guidelines and intercultural communication concepts into U.S college-sponsored study abroad programs. Unpublished M.A. thesis, Portland state University, Portland, OR.

Barna, LaRay M. (1982). Stumbling blocks in intercultural communication. In Samovar, Larry A. \& Porter, Richard E. (Eds.), Intercultural communication: A reader, 3rd ed., 323-29. Belmont, CA: wadsworth Publishing Company.

Batchelder, Donald, \& Warner, Elizabeth G., Eds. (1977). Beyond experience: The experiential approach to cross-cultural education, Brattlelboro, VT: The Experiment Press. 
Baty, Roger M., \& Dold, Eugene. (1977 Spring). Cross-cultural homestays: An analysis of college students' responses after living in an unfamiliar culture. International Journal of Intercultural Relations, Vol. 1 , No. $1,61-76$.

Bennett, Janet M. (1985). Intercultural communication training in cultural self-awareness for study abroad. Unpublished Ph.D. dissertation, University of Minnesota. Ann Arbor, MI. University Microfilms International, \#8606210.

Bennett, Milton J. (1986). Towards ethnorelativism: A developmental model of intercultural sensitivity. In Paige, R. Michael (Ed.), Cross-cultural orientation: New conceptualizations and applications, 27-69. New York, NY: University Press of America.

Bochner, Stephen. (1979). The mediating man and cultural diversity. In Brislin, Richard W. (Ed.), Culture learning: Concepts, applications, and research, 3-17. Honolulu, HA: University Press of Hawaii.

Bochner, Stephen. (1982). The social psychology of cross-cultural relations. In Bochner, Stephen (Ed.), Cultures in contact: studies in cross-cultural contact, 5-44. Oxford: Pergamon Press.

Brislin, Richard W. (1981). Cross-cultural encounters: Face-to-face interaction. New York, NY: Pergamon Press.

Carroll, Laverne. (1974 Spring). old problems and new meanings. Learning Today, Vol. 7, No. 2. ERIC document Reproduction Service No. EJ 098230 IR 500 585).

Coelho, George V. (1962). Personal growth and educational development through working and studying abroad. Journal of Social Issues, Vol. XVIII, No. 1, 55-67.

Condon, John C., \& Yousef, Sathi, F. (1975). An introduction to intercultural communication. Indianapolis, IN: Bobbs-Merrill Educational Publishing.

Dinges, Norman. (1983). Intercultural competence. In Landis, Dan \& Brislin, Richard W. (Eds.), Handbook of intercultural training, Vol. 1, 176-202. New York, NY: Pergamon Press. 
de Sola Pool, Ithiel. (1965). Effects of cross-national contact on national and international images. In Kelman, Herbert C. (Ed.), International behavior: A social psychological analysis, 106-29. New York, NY: Holt, Rinehart \& Winston.

Furnham, Adrian, \& Bochner, Stephen. (1982). Social difficulty in a foreign culture: An empirical analysis of culture shock. In Bochner, Stephen (Ed.), Cultures in contact: Studies in cross-cultural contact, 161-98. Oxford: Pergamon Press.

Goldson, Rose K., Suchman, Edward A., \& Williams, Robin M. (1956). Factors associated with the development of cross-cultural social interaction. Journal of Social Issues, Vol. XVI, No. 1, 49-64.

Gorden, Raymond L. (1974). Living in Latin America: A case study in cross-cultural communication. Chicago, IL: National Textbook Company.

Grove, Cornelius. (1984). Dynamics of international host families, Research Report 27. New York, NY: AFS International/Intercultural Programs, Inc.

Grove, Cornelius, \& Hansel, Bettina. (1988). Dynamics of hosting study. New York, NY: AFS Internationall Intercultural programs, Inc.

Grove, Cornelius, \& Torbiörn, Ingemar. (1985). A new conceptualization of intercultural adjustment and the goals of training. International Journal of Intercultural Communication, Vol. 9, 205-33.

Gudykunst, William B. (1976). A model of group development for intercultural communication workshops. International and Intercultural Communication Annual, III, 86-93.

Gudykunst, William B., Hammer, Mitchell R., \& Wiseman, Richard L. (1977 Summer). An analysis of an integrated approach to cross-cultural training. International Journal of Intercultural Communication, vol. 1, No. 2, 99-110.

Gullahorn, John T., \& Gullahorn, Jeanne E. (1958, Oct.). American objectives in study abroad. Journal of Social Issues, 19(3), 3-47.

Hall, Edward T. (1959). The silent language. Greenwich, CT: Fawcett Publications. 
Hanvey, Robert G. (1979). Cross-cultural awareness. In Smith, Elise E. \& Luce, Louise F. (Eds.), Toward internationalism: Readings in cross-cultural communiation. Rowley, MA: Newberry House Publishers.

Hartung, Elizabeth A. (1983). Difficulties in cultural adjustment and implications for orientation of Japanese high-school students living in America. Unpublished M.A. thesis, UCLA, Los Angeles, CA.

Hawes, Frank, \& Kealey, Daniel J. (1981). An empirical study of Canadian technical assistance: Adaptation and effectiveness of overseas assignment. International Journal of Intercultural Relations, Vol. 5 , 239-58.

Hofman, John E., \& Zak, Itai. (1969). Interpersonal contact and attitude change in a cross-cultural situation. The Journal of Social Psychology, 78, 165-71.

Kagitcibasi, Ciadim. (1978). Cross-national encounters: Turkish students in the United States. International Journal of Intercultural Relations, vol. 2, No. 2 , 141-59.

Kelman, Herbert C. (1962). Changing attitudes through international activities. Journal of Social Issues, XVIII, No. $1,68-87$.

Kelman, Herbert C. (1965). Social-psychological approaches to the study of international relations: Definition of scope. In Kelman, Herbert C. (Ed.), International behavior: A social-psychological analysis, 3-39. New York, NY: Holt, Rinehart \& Winston.

Khan, A. Majeed. (1961). Experience in cross-cultural living. Comilla, East Pakistan: Pakistan Academy for Rural Development.

King, Nancy, \& Huff, Ken. (1985). Host family survival kit: A guide for American host families. Yarmouth, MN: Intercultural Press, Inc.

Lowe, Gary, Askling, Lawrence R., \& Bates, Alyson. (1984). The impact of intercultural contact on host families. International Journal of Intercultural Relations, Vol. 8, 45-60.

Mestenhauser, Josef A. (1983). Learning from sojourners. In Landis, Dan \& Brislin, Richard W. (Eds.), Handbook of intercultural training, vol. 2, 153-85. New York, NY: Pergamon Press. 
Mishler, Anita L. (1965). Personal contact in international exchange. In Kelman, Herbert C. (Ed.), International behavior: A social-psychological analysis, 550-61. New York, NY: Holt, Rinehart \& Winston.

NAFSA. (1982) Principles for practical training experiences for foreign students. Washington, DC.

NAFSA. (1983). NAFSA principles for international educational exchange. Washington, DC.

NAFSA. (1983). NAFSA self-study guide: A guide for the self-assessment of programs and services with international educational exchange at postsecondary institutions. Washington, DC.

Oehlschlaeger, Jan M. Personal interviews. January 1989.

Paige, R. Michael. (1983). Cultures in contact: On intercultural relations among American and foreign students in the United States university context. In Landis, Dan \& Brislin, Richard W. (Eds.), Handbook of intercultural training, Vol. 3, 102-29. New York, NY: Pergamon Press.

Paige, R. Michael. (1986). Trainer competencies: The missing conceptual link in orientation. International Journal of Intercultural Relations, vol. 10, No 1, $135-58$.

Ramsey, Sheila, \& Birk, Judy. (1983). Preparation of North Americans for interaction with Japanese: Considerations of language and communication style. In Landis, Dan \& Brislin, RIchard W. (Eds.), Handbook of intercultural training, Vol. 3, 227-59. New York, NY: Pergamon Press.

Rhinesmith, Stephen J. (1985). Bring home the world: A management guide for community leaders of internationexchange programs. New York, NY: Walker and Company.

Rhinesmith, stephen J. (1983). Negotiating international youth exchange agreements. Washington, DC: Youth Exchange Office, USIA.

Ruben, Brent D., \& Kealey, Daniel J. (1979). Behavioral assessment of communication competency and the prediction of cross-cultural adaptation. International Journal of Intercultural Relations, Vol. $3,15-47$. 
Schild, Erling 0 . (1962). The foreign student as a stranger: Learning the norms of the host culture. The Journal of Social Issues, Vol. XVIII, No. 1, 69-74.

Sell, Deborah K. (1983). Research on attitude change in U.S. students who participate in foreign study experences. International Journal of Intercultural Relations, vol. $7,131-47$.

Selltiz, Claire, \& Cook, stuart W. (1962). Factors influencing attitudes of foreign students toward the host country. Journal of Social Issues, Vol. XVIII, No. 1 , 7-23.

Sharma, Hadhav P., \& Jung, Loren B. (1985). How crosscultural social participation affects the international attitude of U.S. students. International Journal of Intercultural Relations, Vol. 9 , 377-87.

Sherif, Muzafer, \& Sherif, Carolyn H. (1953). Groups in harmony and tension. New York, NY: Harper.

Somer, Robert H., et al. (1959). Young Americans abroad. New York, NY: Columbia University Bureau of Applied Social Research.

Stohl, Cynthia. (1985). The A.M.I.Go. project: A multicultural intergroup opportunity. International Journal of Intercultural Relations, vol. 9, 151-75.

Torrey, Ella R., \& Wheeler, Grace R. (1988). Youth Exchange Homestay Study for the United States Information Agency. Washington, DC: United States Information Agency.

Triandis, Harry C. (1977 Winter). Theoretical framework for evaluation of cross-cultural training effectiveness. International Journal of Intercultural Relations, Vol. $4,19-45$.

Tucker, Raymond K., Weaver, Richard L., \& Berryman-Fink, Cynthia. (1981). Research in speech communication. Englewood Cliffs, NJ: Prentice-Hall, Inc.

United States Information Agency, International Youth Exchange. (1983). One friendship at a time: Your guide to international youth exchange. Washington, DC: The President's Council for International Youth Exchange \& the Consortium for International Youth Exchange. 
Van de Water, Jack. (1970). The American college student and the foreign host family: A comparative evaluation of the Syracuse University foreign study programs. Unpublished Ph.D. dissertation, Syracuse University, Syracuse, NY. 
APPENDIX A

PILOT STUDY COVER LETTER

FINAL SURVEY COVER LETTER 
P.O. Box 260

Manzanita, OR 97130

April 28, 1988

\section{Dear:}

Enclosed are the questionnaires which I spoke to you about last week. I have developed these as part of a master's degree thesis project I am doing in the Department of Speech Communication at Portland State University. The purpose of this research project is to identify a body of goals and objectives that are regarded as significant by host families.

As I discussed with you, this is the pilot study phase of the project. I am asking only five families to participate in this phase; therefore, your contribution is essential. I would appreciate it if you would complete the questionnaires and provide me with any comments or criticisms you care to make about the design and content. If you have any problems or there are items you think should be added, I welcome your suggestions.

An individual copy has been provided for each family member. Those designed for parents are labeled Parent/Guardian; those labeled siblings are for each child who was living at home during the homestay visit.

If you feel your children are able to participate in this survey, I encourage you to have them complete a questionnaire. For very young children, you may have to read the questions to them. If you do not have the time to do this, or feel your child is not old enough to understand, please return his/her questionnaire unanswered.

I will be pleased to send a copy of the results of this study to you as soon as they are available. If you would like a copy, please mark "Yes" to that question on page 11.

After you have completed the questionnaires, I will come to your home to pick them up. At the same time, I would like to talk with you to hear any suggestions for improvement. I will call you on Wednesday, May 4, to arrange a convenient time to come by. In the meantime if you have any questions, please feel free to call me at $368-6179$.

I would like to thank you in advance for your assistance with this project.

Sincerely,

Deborah L. Fisher-Moore 
Portland State Lniversity

P. O. Box 751. Portland. ( RR Y)

July 5,1988

Dear:

Enclosed is a copy of a questionnaire I have developed under the direction of Dr. Milton Bennett as a part of a master's degree thesis project I am doing in the Department of speech Communication at Portland State University.

The purpose of this research project is to identify a body of goals and objectives that are regarded as significant by host family participants that have not been identified through previous research on international exchange.

You were selected for this survey because of your participation either in the Tillamook YMCA's Host Family Program with Japan or in the 4-H Labo/Lex Exchange Program.

By completing this questionnaire you will be helping us to describe the communication process that occurs when international guests and host families live together in a family environment. This information will be useful in developing orientation and training programs that will meet the needs of both visitors and hosts.

We do hope that you will choose to take part in the survey. We are asking only 34 families to participate; therefore, complete data from everyone is essential to the usefulness of the study. We assure you complete confidentiality. We will not ask you at any point to identify yourself, members of your family, or your international visitor. The number on your questionnaire is only for follow-up purposes.

We ask, then, that you will take the time to complete the enclosed questionnaires. I will call you in three or four days to make arrangements to come to your home to collect them. A "Host Parent" questionnaire has been provided for each parent; a "Host Sibling" questionnaire has been provided for each child 14 years of age or older who was living at home during the homestay visit. 
Page Two

By completing the questionnaire, you agree to be a subject. If you choose not to participate in this study, there will be no repercussions to your organization. If you have any questions regarding the manner in which this study is being conducted, you may contact Robert Tinnin, Associate Dean, College of Arts and Letters, 491 Neuberger Hall, Portland State University, Portland, oregon 97207 (503) 464-3514.

We will be pleased to send a copy of the results of this study to you as soon as they are available. If you would like a copy, please mark "Yes" to that question on Page 13 of the questionnaire.

We would like to thank you in advance for your assistance with this project. If you have any questions about the purpose of the project, or have any difficulty with the questionnaire, please feel free to call Deborah Fisher-Moore at 368-6171 (Nehalem).

Sincerely, 
APPENDIX B

PARENT/GUARDIAN QUESTIONNAIRE

\section{SIBLING QUESTIONNAIRE}

Only pages $1-5$ of the sibling questionnaire are included in the appendix. Pages 6-13 are identical to the parent/guardian questionnaire. 
HOST FAMILY GOALS QUESTIONNAIRE

Parent/Guardian

\section{Part I:}

I would like to know how particular goals and objectives apply to your participation as a host family member in an international exchange program. Please answer the following questions as accurately as you can by circling the appropriate number on each scale.

Each question has two parts. Part A asks, "How important was the following goal or objective to your participation in the program?". When answering this part of the question, consider how you felt before your guest's arrival. Part B asks, "To what extent was this goal or objective accomplished?". When answering this part of the question, evaluate how you felt after your guest's departure. Please be sure to answer both Part $A$ and Part $B$ of each question.

Example \#1: As a host family member, how important was it for you: To establish a long-term relationship with someone from another culture?
A) not important $\quad \begin{array}{lllllllll}1 & 2 & 3 & 4 & 5 & 6 & 7 & \text { very important }\end{array}$
To what extent was this accomplished?

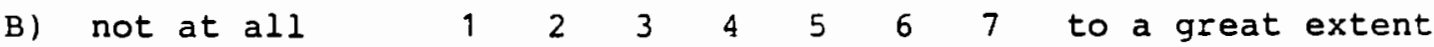

When answering this question, a host mother considered how she felt before the exchange visit began. She had high hopes for establishing a new and enduring relationship with her guest. Her goal was to continue the relationship even after her guest returned home. Therefore, she answered Part $A$ of the question with a $\underline{6}$.

After the visit was over, she felt she had established an enduring relationship with her guest. They promised to correspond with each other, and it is possible they might arrange another visit in the future. She felt her goal was accomplished to a great extent, and therefore she answered Part B with a $\underline{6}$.

1

(please continue) 
Example 2: As a host family member, how important was it for you: To share your family's lifestyle with someone from another culture?
A) not important
123
45
67
7 very important
To what extent was this accomplished?

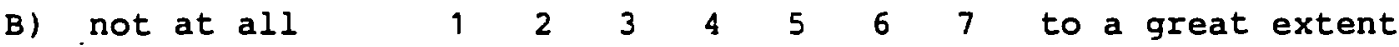

When answering this question, a host father thought about how he felt before the visit began. He had hoped that his foreign guest would want to participate in the many sports activities that his family enjoys. His family is warm and out-going, and it was important to him that his visitor share in their active and informal American lifestyle. Therefore, he answered Part $A$ of the question with a 7 .

However, his guest was not particularly athletic and preferred to listen to American music, shop in the local stores and spend quiet time alone. After the visit was over, the host father was disappointed in his guest's lack of interest in the family activities and felt that his goal had hardly been achieved at all. Therefore, he marked Part $B$ of the question with a $\underline{2}$.

It is important that you answer all of the questions that pertain to your experience. If, however, a question is not relevant, leave it unanswered. Example: Question \#8 asks, "How important was it for you to experience being parents because you do not have children of your own?". If you do have children of your own, this question does not apply to your situation and it is not necessary for you to provide an answer.

I appreciate you taking the time to complete this questionnaire. If you have any questions, please feel free to call me at 368-6171 (Nehalem) for clarification. 


\section{INTERPERSONAL RELATIONSHIPS}

As a host family member, how important was it for you:

1) To establish a long-term relationship with someone from another culture?

A) not important $\begin{array}{lllllllll}1 & 2 & 3 & 4 & 5 & 6 & 7 & \text { very important }\end{array}$

To what extent was this accomplished?

B) not at all $\quad 1 \quad 2 \quad \begin{array}{lllllll} & 1 & 4 & 5 & 6 & 7 & \text { to a great extent }\end{array}$

2) To allow your children to interact with people from other cultures?
A) not important $\quad \begin{array}{llllllll}1 & 2 & 3 & 4 & 5 & 6 & 7 & \text { very important }\end{array}$

To what extent was this accomplished?

B) not at all $\quad \begin{array}{llllllll}1 & 2 & 3 & 4 & 5 & 6 & 7 & \text { to a great extent }\end{array}$

3) To interact on a personal level with someone from a culture in which you are specifically interested?
A) not important $\begin{array}{lllll}1 & 2 & 3 & 4 & 5\end{array}$
To what extent was this accomplished?

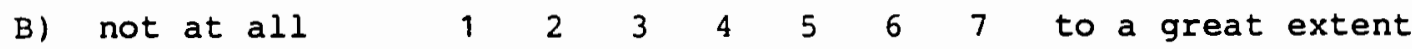

4) To share your family's lifestyle with someone from another culture?
A) not important $\begin{array}{lllllllll}1 & 2 & 3 & 4 & 5 & 6 & 7 & \text { very important }\end{array}$
To what extent was this accomplished?
B) not at all $\quad \begin{array}{llllllll}1 & 2 & 3 & 4 & 5 & 6 & 7 & \text { to a great extent }\end{array}$

\section{FAMILY ISSUES}

As a host family member, how important was it for you:

5) To bring your family closer together by sharing the hosting experience?
A) not important $\begin{array}{lllllllll}1 & 2 & 3 & 4 & 5 & 6 & 7 & \text { very important }\end{array}$
To what extent was this accomplished?
B) not at all $\quad \begin{array}{llllllll}1 & 2 & 3 & 4 & 5 & 6 & 7 & \text { to a great extent }\end{array}$
3
(please continue) 
6) To strengthen your marriage
A) not important $\begin{array}{lllllllll}1 & 2 & 3 & 4 & 5 & 6 & 7 & \text { very important }\end{array}$
To what extent was this accomplished?
B) not at all $\quad 1 \quad 2 \quad \begin{array}{lllllll} & 3 & 4 & 5 & 6 & 7 & \text { to a great extent }\end{array}$

7) To experience being parents because you do not have children of your own?
A) not important $\quad \begin{array}{llllllll} & 2 & 3 & 4 & 5 & 6 & 7 & \text { very important }\end{array}$
To what extent was this accomplished?
B) not at all $\quad 1 \quad 2 \quad \begin{array}{lllllll} & 3 & 4 & 5 & 6 & 7 & \text { to a great extent }\end{array}$

8) To experience parenting a girl/boy because you do not have a daughter/son of your own?
A) not important $\quad \begin{array}{llllllll} & 2 & 3 & 4 & 5 & 6 & 7 & \text { very important }\end{array}$
To what extent was this accomplished?

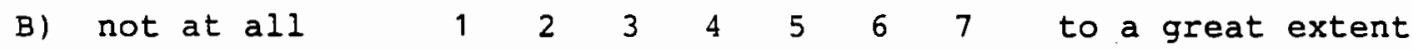

9) To have another young person around for a while because your own children no longer live at home?
A) not important $19 \begin{array}{llllllll} & 3 & 3 & 4 & 5 & 6 & 7 & \text { very important }\end{array}$
To what extent was this accomplished?

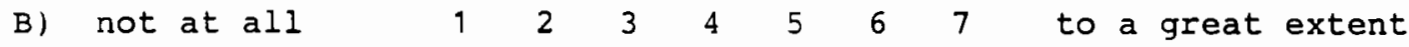

10) To provide companionship for your child?
A) not important $\quad \begin{array}{llllllll}1 & 2 & 3 & 4 & 5 & 6 & 7 & \text { very important }\end{array}$
To what extent was this accomplished?

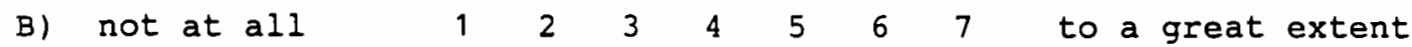

11) To please your child/ren who heard about hosting and wanted to volunteer?
A) not important $\quad \begin{array}{llllllll}1 & 2 & 3 & 4 & 5 & 6 & 7 & \text { very important }\end{array}$
To what extent was this accomplished?
B) not at all $\quad 1 \quad 2 \quad \begin{array}{lllllll} & 3 & 4 & 5 & 6 & 7 & \text { to a great extent }\end{array}$
(please $\stackrel{4}{\text { continue) }}$ 


\section{GUESTS AS A RESOURCE}

As a host family member, how important was it for you:

12) To bring a distinctive individual into your home who may act as a positive role model for your own children?

A) not important $1 \begin{array}{llllllll}1 & 2 & 3 & 4 & 5 & 6 & 7 & \text { very important }\end{array}$

To what extent was this accomplished?

B) not at all $\quad \begin{array}{llllllll}1 & 2 & 3 & 4 & 5 & 6 & 7 & \text { to a great extent }\end{array}$

13) To have a guest who would add to family income?

A) not important $\quad \begin{array}{llllllll}1 & 2 & 3 & 4 & 5 & 6 & 7 & \text { very important }\end{array}$

To what extent was this accomplished?

B) not at all $\quad \begin{array}{llllllll}1 & 2 & 3 & 4 & 5 & 6 & 7 & \text { to a great extent }\end{array}$

14) To provide additional household help?
A) not important $\quad \begin{array}{llllllll}1 & 2 & 3 & 4 & 5 & 6 & 7 & \text { very important }\end{array}$
To what extent was this accomplished?
B) not at all $\quad 1 \quad 2 \quad \begin{array}{lllllll} & 3 & 4 & 5 & 6 & 7 & \text { to a great extent }\end{array}$

15) To provide help in.taking care of your own children?
A) not important $\quad \begin{array}{llllllll}1 & 2 & 3 & 4 & 5 & 6 & 7 & \text { very important }\end{array}$
To what extent was this accomplished?
B) not at all $\quad 1 \quad 2 \quad \begin{array}{lllllll} & 3 & 4 & 5 & 6 & 7 & \text { to a great extent }\end{array}$

16) To visit your guest's country in the future? (Acting as a host family may provide personal contacts in his or her country.)
A) not important $\quad \begin{array}{llllllll}1 & 2 & 3 & 4 & 5 & 6 & 7 & \text { very important }\end{array}$
To what extent was this accomplished?
B) not at all $\quad \begin{array}{llllllll}1 & 2 & 3 & 4 & 5 & 6 & 7 & \text { to a great extent }\end{array}$ 


\section{PERSONAL FACTORS}

As a host family member, how important was it for you:

17) To further your own personal development?
A) not important $\begin{array}{llllllll}1 & 2 & 3 & 4 & 5 & 6 & 7 & \text { very important }\end{array}$
To what extent was this accomplished?
B) not at all $\quad \begin{array}{llllllll}1 & 2 & 3 & 4 & 5 & 6 & 7 & \text { to a great extent }\end{array}$

18) To further family members' personal development?
A) not important $\begin{array}{llllllll}1 & 2 & 3 & 4 & 5 & 6 & 7 & \text { very important }\end{array}$
To what extent was this accomplished?

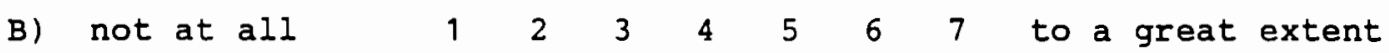

19) To further your guest's personal development?
A) not important $\begin{array}{llllllll}1 & 2 & 3 & 4 & 5 & 6 & 7 & \text { very important }\end{array}$
To what extent was this accomplished?
B) not at all $\quad \begin{array}{llllllll} & 1 & 2 & 3 & 4 & 5 & 6 & 7\end{array}$ to a great extent

20) To provide this opportunity for someone else because you participated in an exchange program yourself?
A) not important $\begin{array}{llllllll}1 & 2 & 3 & 4 & 5 & 6 & 7 & \text { very important }\end{array}$
To what extent was this accomplished?
B) not at all $\quad \begin{array}{llllllll} & 1 & 2 & 3 & 4 & 5 & 6 & 7\end{array}$ to a great extent

21) To have fun?
A) not important $\quad \begin{array}{llllllll}1 & 2 & 3 & 4 & 5 & 6 & 7 & \text { very important }\end{array}$
To what extent was this accomplished?

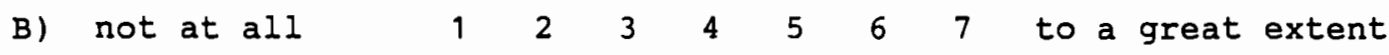

22) To satisfy your curiosity about hosting?
A) not important $\quad \begin{array}{llllllll}1 & 2 & 3 & 4 & 5 & 6 & 7 & \text { very important }\end{array}$
To what extent was this accomplished?
B) not at all $\quad \begin{array}{llllllll}1 & 2 & 3 & 4 & 5 & 6 & 7 & \text { to a great extent }\end{array}$
6
(please continue) 


\section{EDUCATIONAL OPPORTUNITIES}

As a host family member, how important was it for you:

23) To have an educational experience through hosting someone from another culture?
A) not important
$\begin{array}{lllll}1 & 2 & 3 & 4\end{array}$
$\begin{array}{lll}6 & 7 & \text { very important }\end{array}$
To what extent was this accomplished?
B) not at all $\quad \begin{array}{llllllll}1 & 2 & 3 & 4 & 5 & 6 & 7 & \text { to a great extent }\end{array}$

24) To achieve understanding of another culture by bringing someone into your home who knows about that culture?
A) not important $\begin{array}{llllllll}1 & 2 & 3 & 4 & 5 & 6 & 7 & \text { very important }\end{array}$
To what extent was this accomplished?
B) not at all $\quad 1 \quad 2 \quad 3 \quad \begin{array}{llllll}4 & 5 & 6 & 7 & \text { to a great extent }\end{array}$

25) To learn or practice the language of your guest?
A) not important $\quad \begin{array}{llllllll}1 & 2 & 3 & 4 & 5 & 6 & 7 & \text { very important }\end{array}$
To what extent was this accomplished?
B) not at all $\quad 1 \quad 2 \quad \begin{array}{lllllll} & 3 & 4 & 5 & 6 & 7 & \text { to a great extent }\end{array}$

26) To provide your guest with an opportunity for intensive foreign language study?
A) not important $\quad \begin{array}{llllllll}1 & 2 & 3 & 4 & 5 & 6 & 7 & \text { very important }\end{array}$
To what extent was this accomplished?
B) not at all $\quad \begin{array}{llllllll}1 & 2 & 3 & 4 & 5 & 6 & 7 & \text { to a great extent }\end{array}$

27) To aid in the educational or professional development of your guest?
A) not important $\quad \begin{array}{llllllll}1 & 2 & 3 & 4 & 5 & 6 & 7 & \text { very important }\end{array}$
To what extent was this accomplished?
B) not at all $\quad 1 \quad 2 \quad \begin{array}{lllllll} & 3 & 4 & 5 & 6 & 7 & \text { to a great extent }\end{array}$

28) To sensitize your guest to his/her own cultural identity?
A) not important $\quad \begin{array}{llllllll}1 & 2 & 3 & 4 & 5 & 6 & 7 & \text { very important }\end{array}$
To what extent was this accomplished?
B) not at all $\quad 1 \quad 2 \quad \begin{array}{lllllll} & 3 & 4 & 5 & 6 & 7 & \text { to a great extent }\end{array}$ 
(EDUCATIONAL OPPORTUNITIES continued...)

29) To learn about your own heritage better? (that is, if from French ancestry, having a French guest.)
A) not important
$\begin{array}{lllll}1 & 2 & 3 & 4 & 5\end{array}$
$\begin{array}{lll}6 & 7 & \text { very important }\end{array}$
To what extent was this accomplished?
B) not at all $\quad \begin{array}{llllllll}1 & 2 & 3 & 4 & 5 & 6 & 7 & \text { to a great extent }\end{array}$

\section{COMMUNITY INVOLVEMENT}

As a host family member, how important was it for you:

30) To share the experience of others in the community who have had a good hosting experience?
A) not important $\quad \begin{array}{llllllll}1 & 2 & 3 & 4 & 5 & 6 & 7 & \text { very important }\end{array}$
To what extent was this accomplished?
B) not at all $\quad \begin{array}{llllllll}1 & 2 & 3 & 4 & 5 & 6 & 7 & \text { to a great extent }\end{array}$

31) To agree to requests from program coordinators who asked you to fill in as a host family?
A) not important $\quad \begin{array}{llllllll}1 & 2 & 3 & 4 & 5 & 6 & 7 & \text { very important }\end{array}$
To what extent was this accomplished?
B) not at all $\quad 1 \quad 2 \quad \begin{array}{lllllll} & 3 & 4 & 5 & 6 & 7 & \text { to a great extent }\end{array}$

32) To do something that will allow you to be well thought of in the community?
A) not important $\begin{array}{lllllllll}1 & 2 & 3 & 4 & 5 & 6 & 7 & \text { very important }\end{array}$
To what extent was this accomplished?
B) not at all $\quad \begin{array}{llllllll} & 1 & 2 & 3 & 4 & 5 & 6 & 7\end{array}$ to a great extent

$$
\text { (please continue) }
$$




\section{DEVELOPING VALUES AND ATTITUDES}

As a host family member, how important was it for you:

33) To do something different, to accept a risky and unpredictable challenge?
A) not important $\quad \begin{array}{llllllll}1 & 2 & 3 & 4 & 5 & 6 & 7 & \text { very important }\end{array}$
To what extent was this accomplished?
B) not at all $\quad \begin{array}{llllllll}1 & 2 & 3 & 4 & 5 & 6 & 7 & \text { to a great extent }\end{array}$

34) To provide members of your family with the opportunity to change their views of people from other cultures?
A) not important $\begin{array}{llllllll}1 & 2 & 3 & 4 & 5 & 6 & 7 & \text { very important }\end{array}$
To what extent was this accomplished?
B) not at all $\quad \begin{array}{llllllll}1 & 2 & 3 & 4 & 5 & 6 & 7 & \text { to a great extent }\end{array}$

35) To learn about Americans from the perspective of a person from another culture?
A) not important $\begin{array}{lllllllll}1 & 2 & 3 & 4 & 5 & 6 & 7 & \text { very important }\end{array}$
To what extent was this accomplished?
B) not at all $\quad \begin{array}{llllllll}1 & 2 & 3 & 4 & 5 & 6 & 7 & \text { to a great extent }\end{array}$

36) To show someone from another culture the good things about your values and the American way of life?
A) not important $\begin{array}{llllllll}1 & 2 & 3 & 4 & 5 & 6 & 7 & \text { very important }\end{array}$
To what extent was this accomplished?
B) not at all $\quad \begin{array}{llllllll}1 & 2 & 3 & 4 & 5 & 6 & 7 & \text { to a great extent }\end{array}$

37.) To develop friends and supporters for the American way of life by giving persons from other countries a better understanding of our political system?
A) not important $\quad \begin{array}{llllllll}1 & 2 & 3 & 4 & 5 & 6 & 7 & \text { very important }\end{array}$
To what extent was this accomplished?

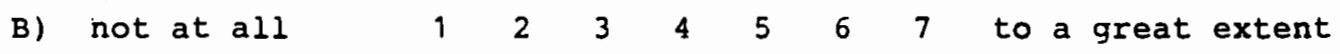
9
(please continue) 


\section{EXPRESSING YOUR PHILOSOPHY OF LIFE}

As a host family member, how important was it for you:

38) To put your religious principles into practice?
A) not important $\begin{array}{llllllll}1 & 2 & 3 & 4 & 5 & 6 & 7\end{array}$
very important
To what extent was this accomplished?

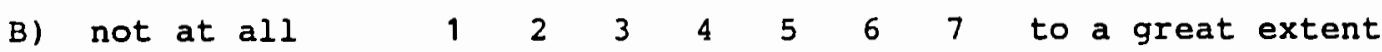

39) To have a personal intercultural experience?
A) not importan
123
4
$\begin{array}{lll}5 & 6 & 7\end{array}$
very important
To what extent was this accomplished?
B) not at all $\quad \begin{array}{llllllll} & 1 & 2 & 3 & 4 & 5 & 6 & 7\end{array}$ to a great extent

40) To increase your intercultural knowledge for the general welfare of humanity?
A) not important $\quad \begin{array}{llllllll}1 & 2 & 3 & 4 & 5 & 6 & 7 & \text { very important }\end{array}$
To what extent was this accomplished?

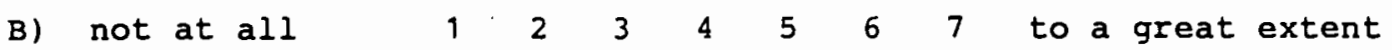

41) To increase your guest's intercultural knowledge for the general welfare of humanity?
A) not important $1 \begin{array}{llllllll}1 & 2 & 3 & 4 & 5 & 6 & 7 & \text { very important }\end{array}$
To what extent was this accomplished?
B) not at all $\quad \begin{array}{llllllll}1 & 2 & 3 & 4 & 5 & 6 & 7 & \text { to a great extent }\end{array}$

42) To promote international understanding and good will among the peoples of the world as a contribution to peace?
A) not important $\quad \begin{array}{llllllll}1 & 2 & 3 & 4 & 5 & 6 & 7 & \text { very important }\end{array}$
To what extent was this accomplished?
B) not at all $\quad \begin{array}{llllllll}1 & 2 & 3 & 4 & 5 & 6 & 7 & \text { to a great extent }\end{array}$

43) To provide an opportunity to an individual from a less developed society who can return and contribute to the economic, social or political development of their own country
A) not important $\begin{array}{llllllll}1 & 2 & 3 & 4 & 5 & 6 & 7 & \text { very important }\end{array}$
To what extent was this accomplished?
B) not at at all $\quad \begin{array}{llllllll}1 & 2 & 3 & 4 & 5 & 6 & 7 & \text { to a great extent }\end{array}$ 


\section{Part II:}

Other than those goals mentioned above, what additional factors, if any, do you regard as relevant to your volunteering as a host family for an international exchange program?

Additional Comments:

11

(please continue) 
A. Please check one:

Host father

Host brother

Host mother

other

B. Your age:

C. Last year of school completed:

D. Your occupation:

E. Number of children in your family

\begin{tabular}{|c|c|c|}
\hline Age & Male Female & $\begin{array}{l}\text { Living at home during } \\
\text { homestay visit? (yes/no) }\end{array}$ \\
\hline \multicolumn{3}{|l|}{1.} \\
\hline \multicolumn{3}{|l|}{$\underline{2 .}$} \\
\hline \multicolumn{3}{|l|}{3.} \\
\hline \multicolumn{3}{|l|}{4.} \\
\hline \multicolumn{3}{|l|}{5.} \\
\hline 6. & 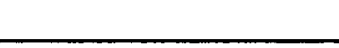 & \\
\hline
\end{tabular}

F. How many times have you participated as a host family in an international exchange program lasting three weeks or longer?

From what country/countries did your guest/s come?

Based on your previous experience, would you act as a host family again?

Yes No

Why? 
G. Was orientation/training made available to you as a host family member? Yes No

Did you participate? Yes No

How much time did it involve?

When was it offered?

Before the visit

During the visit

After the visit

What was the content of the training/orientation?

H. If you were to host again, and orientation/training were offered, would you participate? Yes No

If yes, when would you like it to be offered?

Before the visit

During the visit

After the visit

What would you like to see included in these sessions?

I. Would you like a copy of the results of this study sent to you? Yes No

Thank you for your cooperation. 
HOST FAMILY GOALS QUESTIONNAIRE

Sibling

\section{Part I:}

I would like to know how particular goals and objectives apply to your participation as a host family member in an international exchange program. Please answer the following questions as accurately as you can by circling the appropriate number on each scale.

Each question has two parts. Part A asks, "How important was the following goal or objective to your participation in the program?". When answering this part of the question, consider how you felt before your guest's arrival. Part B asks, "To what extent was this goal or objective accomplished?". When answering this part of the question, evaluate how you felt after your guest's departure. Please be sure to answer both Part A and Part $B$ of each question.

Example \#1: As a host family member, how important was it for you: To establish a long-term relationship with someone from another culture?

A) not important $\quad \begin{array}{llllllll}1 & 2 & 3 & 4 & 5 & 6 & 7 & \text { very important }\end{array}$

To what extent was this accomplished?

B) not at all $\quad 1 \quad 2 \quad \begin{array}{lllllll} & 3 & 4 & 5 & 6 & 7 & \text { to a great extent }\end{array}$

When answering this question, a host mother considered how she felt before the exchange visit began. She had high hopes for establishing a new and enduring relationship with her guest. Her goal was to continue the relationship even after her guest returned home. Therefore, she answered Part $A$ of the question with a $\underline{6}$.

After the visit was over, she felt she had established an enduring relationship with her guest. They promised to correspond with each other, and it is possible they might arrange another visit in the future. She felt her goal was accomplished to a great extent, and therefore she answered Part B with a $\underline{6}$. 
Example 2: As a host family member, how important was it for you: To share your family's lifestyle with someone from another culture?

A) not important $1 \begin{array}{llllllll}2 & 3 & 4 & 5 & 6 & 7 & \text { very important }\end{array}$

To what extent was this accomplished?

B) not at all $\quad 1 \quad 2 \quad 3 \quad 4 \quad 5 \quad 6 \quad 7$ to a great extent

When answering this question, a host father thought about how he felt before the visit began. He had hoped that his foreign guest would want to participate in the many sports activities that his family enjoys. His family is warm and out-going, and it was important to him that his visitor share in their active and informal American lifestyle. Therefore, he answered Part $A$ of the question with a 7 .

However, his guest was not particularly athletic and preferred to listen to American music, shop in the local stores and spend quiet time alone. After the visit was over, the host father was disappointed in his guest's lack of interest in the family activities and felt that his goal had hardly been achieved at all. Therefore, he marked Part $B$ of the question with a $\underline{2}$.

It is important that you answer all of the questions that pertain to your experience. If, however, a question is not relevant, leave it unanswered. Example: Question \#8 asks, "How important was it for you to experience being parents because you do not have children of your own?". If you do have children of your own, this question does not apply to your situation and it is not necessary for you to provide an answer.

I appreciate you taking the time to complete this questionnaire. If you have any questions, please feel free to call me at 368-6171 (Nehalem) for clarification. 


\section{INTERPERSONAL RELATIONSHIPS}

As a host family member, how important was it for you:

1) To establish a long-term relationship with someone from another culture?
A) not important $\begin{array}{lllllllll}1 & 2 & 3 & 4 & 5 & 6 & 7 & \text { very important }\end{array}$
To what extent was this accomplished?

B) not at all $\quad 1 \quad 2 \quad 3 \quad \begin{array}{llllll} & 4 & 5 & 6 & 7 & \text { to a great extent }\end{array}$

2) To interact on a personal level with someone from a culture in which you are specifically interested?
A) not important $\quad \begin{array}{llllllll}1 & 2 & 3 & 4 & 5 & 6 & 7 & \text { very important }\end{array}$
To what extent was this accomplished?

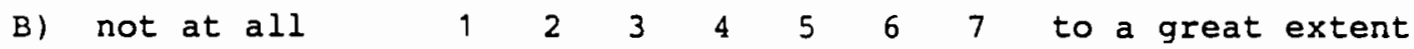

3) To share your family's lifestyle with someone from another culture?
A) not important $\begin{array}{lllllllll}1 & 2 & 3 & 4 & 5 & 6 & 7 & \text { very important }\end{array}$ To what extent was this accomplished?
B) not at all $\quad 1 \quad 2 \quad \begin{array}{lllllll} & 3 & 4 & 5 & 6 & 7 & \text { to a great extent }\end{array}$

$$
\text { (please } \stackrel{3}{\text { continue) }}
$$




\section{FAMILY ISSUES}

As a host family member, how important was it for you:

4) To bring your family closer together by sharing the hosting experience?
A) not important $\quad \begin{array}{llllllll}1 & 2 & 3 & 4 & 5 & 6 & 7 & \text { very important }\end{array}$
To what extent was this accomplished?
B) not at all $\quad 1 \quad 2 \quad \begin{array}{lllllll} & 3 & 4 & 5 & 6 & 7 & \text { to a great extent }\end{array}$

5) To experience having a brother/sister because you do not have one of your own?

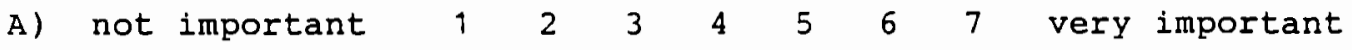
To what extent was this accomplished?

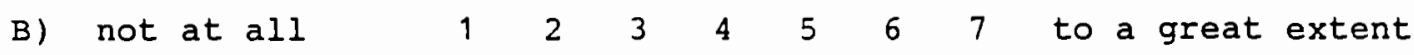

6) To have another young person around for a while because there are no other children living at home with you and your parents?

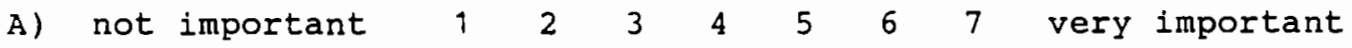
To what extent was this accomplished?

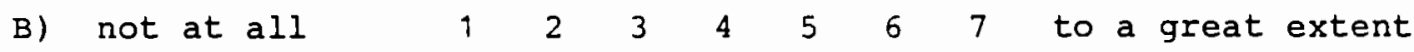

7) To please your parents who heard about hosting and wanted to volunteer?
A) not important $\quad \begin{array}{llllllll}1 & 2 & 3 & 4 & 5 & 6 & 7 & \text { very important }\end{array}$
To what extent was this accomplished?
B) not at all $\quad 1 \quad 2 \quad 3 \quad 4 \quad 4 \quad 5 \quad 6 \quad 7 \quad$ to a great extent
(please continue) 


\section{GUESTS AS A RESOURCE}

As a host family member, how important was it for you:

8) To have a guest who would add to family income?
A) not important
1
23
45
67 very important
To what extent was this accomplished?
B) not at all
$\begin{array}{lllll}1 & 2 & 3 & 4 & 5\end{array}$
67 to a great extent

9) To provide additional household help?
A) not important $\begin{array}{llllllll}1 & 2 & 3 & 4 & 5 & 6 & 7 & \text { very important }\end{array}$
To what extent was this accomplished?
B) not at all $\quad 1 \quad 2 \quad 3 \quad 4 \quad 5 \quad 6 \quad 7$ to a great extent

10) To provide help in taking care of other children in your family?
A) not important $\begin{array}{llllllll}1 & 2 & 3 & 4 & 5 & 6 & 7 & \text { very important }\end{array}$
To what extent was this accomplished?
B) not at all $\quad \begin{array}{llllllll} & 2 & 3 & 4 & 5 & 6 & 7 & \text { to a great extent }\end{array}$

11) To visit your guest's country in the future? (Acting as a host family may provide personal contacts in his or her country.)
A) not important $\begin{array}{lllllllll}1 & 2 & 3 & 4 & 5 & 6 & 7 & \text { very important }\end{array}$
To what extent was this accomplished?
B) not at all
$2 \quad 3 \quad 4 \quad 5$
5
(please continue) 


\section{APPENDIX C}

\section{TABLE X}

RANK ORDER OF LITERATURE-BASED GOALS RATED $\geq 5.00$ FOR ACHIEVEMENT BY HOST FAMILIES

\section{TABLE XI}

RANK ORDER OF NON-LITERATURE-BASED GOALS RATED

$\geq 5.00$ FOR ACHIEVEMENT BY HOST FAMILIES 
TABLE $X$

MEAN RATINGS FOR IMPORTANCE AND ACHIEVEMENT

OF LITERATURE-BASED GOAIS

\author{
Questionnaire Item \\ and Item Number \\ 1. Establish long-term \\ relationship \\ 2. Children interact \\ with guest \\ 3. Interact with \\ specific culture \\ 4. Share family's \\ lifestyle
}

17. Develop personally

18. Develop family personally

19. Develop guest personally

23. Educate self

24. Understand another culture

25. Practice foreign language

26. Help guest learn English

27. Aid guest's educ'l development

28. Sensitize guest to cultural identity

34. Change family views of cultures

35. Get guest's perception of Americans

36. Show guest American values/way of life
Importance/

Achievement

$\mathrm{N}$

Importance

Achievement

Importance

Achievement

Importance

Achievement

Importance

Achievement

Importance

Achievement

Importance

Achievement

Importance

Achievement

Importance

Achievement

Importance

Achievement

Importance

Achievement

Importance

Achievement

Importance

Achievement

Importance

Achievement

Importance

Achievement

Importance

Achievement

Importance

Achievement
$\mathrm{N}$ Mean

SD

Rng

$\begin{array}{llll}67 & 4.79 & 1.67 & 1-7\end{array}$

$\begin{array}{llll}67 & 4.46 & 1.73 & 1-7\end{array}$

$\begin{array}{llll}51 & 6.14 & 1.02 & 3-7\end{array}$

$51 \quad 5.84 \quad 1.16 \quad 3-7$

$\begin{array}{llll}65 & 5.11 & 1.59 & 1-7\end{array}$

$\begin{array}{llll}65 & 5.03 & 1.40 & 1-7\end{array}$

$\begin{array}{llll}68 & 5.51 & 1.26 & 2-7\end{array}$

$\begin{array}{llll}68 & 5.56 & 1.30 & 2-7\end{array}$

$\begin{array}{llll}66 & 4.39 & 1.73 & 1-7\end{array}$

$\begin{array}{llll}66 & 4.64 & 1.72 & 1-7\end{array}$

$\begin{array}{llll}64 & 4.69 & 1.83 & 1-7\end{array}$

$\begin{array}{llll}64 & 4.58 & 1.73 & 1-7\end{array}$

$\begin{array}{llll}66 & 5.35 & 1.36 & 1-7\end{array}$

$\begin{array}{llll}65 & 5.32 & 1.31 & 2-7\end{array}$

$\begin{array}{llll}67 & 5.13 & 1.81 & 1-7\end{array}$

$\begin{array}{llll}65 & 5.34 & 1.63 & 1-7\end{array}$

$68 \quad 5.34 \quad 1.63 \quad 1-7$

$\begin{array}{llll}66 & 5.55 & 1.31 & 1-7\end{array}$

$\begin{array}{llll}67 & 3.16 & 2.10 & 1-7\end{array}$

$\begin{array}{llll}66 & 2.97 & 1.89 & 1-7\end{array}$

$\begin{array}{llll}65 & 3.72 & 1.88 & 1-7\end{array}$

$\begin{array}{llll}64 & 3.98 & 1.87 & 1-7\end{array}$

$\begin{array}{llll}67 & 4.64 & 1.86 & 1-7\end{array}$

$\begin{array}{llll}66 & 4.79 & 1.54 & 1-7\end{array}$

$\begin{array}{llll}60 & 3.43 & 2.06 & 1-7\end{array}$

$\begin{array}{llll}58 & 3.53 & 1.97 & 1-7\end{array}$

$\begin{array}{llll}65 & 4.78 & 1.10 & 1-7\end{array}$

$\begin{array}{llll}65 & 4.74 & 1.89 & 1-7\end{array}$

$\begin{array}{llll}66 & 4.48 & 1.99 & 1-7\end{array}$

$\begin{array}{llll}66 & 4.55 & 1.81 & 1-7\end{array}$

$\begin{array}{llll}67 & 5.22 & 1.52 & 1-7\end{array}$

$\begin{array}{llll}67 & 5.46 & 1.41 & 2-7\end{array}$

(continued) 
TABLE $\mathrm{x}$

(continued)

Questionnaire Item

Importance/

and Item Number

Achievement

$\mathrm{N} \quad$ Mean

SD Rng

37. Develop support for political system

Importance $\quad \begin{array}{llll}64 & 3.53 & 2.19 & 1-7\end{array}$

Achievement $\begin{array}{llll}64 & 3.23 & 2.02 & 2-7\end{array}$

40. Increase knowledge for human welfare

41. Increase guest's knowledge

Importance

Achievement

$\begin{array}{llll}64 & 4.41 & 1.96 & 1-7\end{array}$

Importance

62

4.35

1.89

$1-7$

Achievement

$\begin{array}{llll}64 & 4.41 & 2.14 & 1-7\end{array}$

Importance

64

$4.22 \quad 1.96$

$1-7$

42. Promote internat' 1 goodwill/peace

Achievement

65

5.08

1.80

$1-7$

Importance

Achievement

50

5.00

1.70

$1-7$

43. Aid a less developed society

$1-7$

$\begin{array}{llll}49 & 3.14 & 2.04 & 1-7\end{array}$ 
TABLE XI

MEAN RATINGS FOR IMPORTANCE AND ACHIEVEMENT OF NON-LITERATURE-BASED GOALS

\begin{tabular}{|c|c|c|c|c|c|}
\hline $\begin{array}{l}\text { Questionnaire Item } \\
\text { and Item Number }\end{array}$ & $\begin{array}{l}\text { Importance/ } \\
\text { Achievement }\end{array}$ & $\mathrm{N}$ & Mean & $S D$ & Rng \\
\hline 5. Bring family closer & $\begin{array}{l}\text { Importance } \\
\text { Achievement }\end{array}$ & $\begin{array}{l}67 \\
66\end{array}$ & $\begin{array}{l}4.28 \\
4.58\end{array}$ & $\begin{array}{l}1.90 \\
1.92\end{array}$ & $\begin{array}{l}1-7 \\
1-7\end{array}$ \\
\hline 6. Strengthen marriage & $\begin{array}{l}\text { Importance } \\
\text { Achievement }\end{array}$ & $\begin{array}{l}46 \\
42\end{array}$ & $\begin{array}{l}2.00 \\
2.50\end{array}$ & $\begin{array}{l}1.70 \\
1.80\end{array}$ & $\begin{array}{l}1-7 \\
1-7\end{array}$ \\
\hline 7. Experience parenting & $\begin{array}{l}\text { Importance } \\
\text { Achievement }\end{array}$ & $\begin{array}{l}3 \\
3\end{array}$ & $\begin{array}{l}2.67 \\
3.67\end{array}$ & $\begin{array}{l}2.89 \\
2.31\end{array}$ & $\begin{array}{l}1-6 \\
1-5\end{array}$ \\
\hline $\begin{array}{l}\text { 8. Experience boy/girl } \\
\text { in family }\end{array}$ & $\begin{array}{l}\text { Importance } \\
\text { Achievement }\end{array}$ & $\begin{array}{l}11 \\
11\end{array}$ & $\begin{array}{l}2.45 \\
3.09\end{array}$ & $\begin{array}{l}1.97 \\
2.07\end{array}$ & $\begin{array}{l}1-7 \\
1-7\end{array}$ \\
\hline $\begin{array}{l}\text { 9. Have child live in } \\
\text { home again }\end{array}$ & $\begin{array}{l}\text { Importance } \\
\text { Achievement }\end{array}$ & $\begin{array}{l}12 \\
11\end{array}$ & $\begin{array}{l}3.33 \\
3.91\end{array}$ & $\begin{array}{l}2.15 \\
2.16\end{array}$ & $\begin{array}{l}1-7 \\
1-7\end{array}$ \\
\hline $\begin{array}{l}\text { 10. Companionship for } \\
\text { own child }\end{array}$ & $\begin{array}{l}\text { Importance } \\
\text { Achievement }\end{array}$ & $\begin{array}{l}41 \\
41\end{array}$ & $\begin{array}{l}2.36 \\
3.17\end{array}$ & $\begin{array}{l}1.76 \\
2.02\end{array}$ & $\begin{array}{l}1-7 \\
1-7\end{array}$ \\
\hline $\begin{array}{l}\text { 11. Please own children/ } \\
\text { parents }\end{array}$ & $\begin{array}{l}\text { Importance } \\
\text { Achievement }\end{array}$ & $\begin{array}{l}55 \\
53\end{array}$ & $\begin{array}{l}3.44 \\
4.00\end{array}$ & $\begin{array}{l}2.18 \\
2.48\end{array}$ & $\begin{array}{l}1-7 \\
1-7\end{array}$ \\
\hline $\begin{array}{l}\text { 12. Positive role model } \\
\text { for own children }\end{array}$ & $\begin{array}{l}\text { Importance } \\
\text { Achievement }\end{array}$ & $\begin{array}{l}48 \\
47\end{array}$ & $\begin{array}{l}3.12 \\
3.28\end{array}$ & $\begin{array}{l}2.10 \\
1.96\end{array}$ & $\begin{array}{l}1-7 \\
1-7\end{array}$ \\
\hline $\begin{array}{l}\text { 14. Provide household } \\
\text { help }\end{array}$ & $\begin{array}{l}\text { Importance } \\
\text { Achievement }\end{array}$ & $\begin{array}{l}62 \\
57\end{array}$ & $\begin{array}{l}1.40 \\
2.12\end{array}$ & $\begin{array}{l}1.03 \\
1.85\end{array}$ & $\begin{array}{l}1-6 \\
1-7\end{array}$ \\
\hline $\begin{array}{l}\text { 15. Add childcare for } \\
\text { own children }\end{array}$ & $\begin{array}{l}\text { Importance } \\
\text { Achievement }\end{array}$ & $\begin{array}{l}59 \\
55\end{array}$ & $\begin{array}{l}1.19 \\
1.60\end{array}$ & $\begin{array}{r}.90 \\
1.45\end{array}$ & $\begin{array}{l}1-5 \\
1-7\end{array}$ \\
\hline $\begin{array}{l}\text { 16. Establish travel } \\
\text { contact }\end{array}$ & $\begin{array}{l}\text { Importance } \\
\text { Achievement }\end{array}$ & $\begin{array}{l}67 \\
59\end{array}$ & $\begin{array}{l}3.15 \\
3.05\end{array}$ & $\begin{array}{l}1 \cdot 97 \\
2 \cdot 10\end{array}$ & $\begin{array}{l}1-7 \\
1-7\end{array}$ \\
\hline $\begin{array}{l}\text { 20. Relive own exchange } \\
\text { experience }\end{array}$ & $\begin{array}{l}\text { Importance } \\
\text { Achievement }\end{array}$ & $\begin{array}{l}26 \\
26\end{array}$ & $\begin{array}{l}2.96 \\
3.27\end{array}$ & $\begin{array}{l}2.25 \\
2.32\end{array}$ & $\begin{array}{l}1-7 \\
1-7\end{array}$ \\
\hline 21. Have fun & $\begin{array}{l}\text { Importance } \\
\text { Achievement }\end{array}$ & $\begin{array}{l}62 \\
62\end{array}$ & $\begin{array}{l}5.71 \\
5.73\end{array}$ & $\begin{array}{l}1.79 \\
1.47\end{array}$ & $\begin{array}{l}1-7 \\
1-7\end{array}$ \\
\hline $\begin{array}{l}\text { 22. Satisfy curiosity } \\
\text { about hosting }\end{array}$ & $\begin{array}{l}\text { Importance } \\
\text { Achievement }\end{array}$ & $\begin{array}{l}60 \\
60\end{array}$ & $\begin{array}{l}3.98 \\
5.00\end{array}$ & $\begin{array}{l}1.79 \\
1.84\end{array}$ & $\begin{array}{l}1-7 \\
1-7\end{array}$ \\
\hline $\begin{array}{l}\text { 29. Learn about own } \\
\text { heritage }\end{array}$ & $\begin{array}{l}\text { Importance } \\
\text { Achievement }\end{array}$ & $\begin{array}{l}42 \\
41\end{array}$ & $\begin{array}{l}1.86 \\
1.63\end{array}$ & $\begin{array}{l}1.57 \\
1.32\end{array}$ & $\begin{array}{l}1-7 \\
1-5\end{array}$ \\
\hline $\begin{array}{l}\text { 30. Share community } \\
\text { hosting }\end{array}$ & $\begin{array}{l}\text { Importance } \\
\text { Achievement } \\
\text { (continued) }\end{array}$ & $\begin{array}{l}66 \\
66\end{array}$ & $\begin{array}{l}4.47 \\
4.83\end{array}$ & $\begin{array}{l}1.89 \\
1.74\end{array}$ & $\begin{array}{l}1-7 \\
1-7\end{array}$ \\
\hline
\end{tabular}


TABLE XI

(continued)

Questionnaire Item and Item Number

31. Help program coordinator

32. Gain recognition in the community

33. Risk unpredictable challenge

38. Practice religious principles

39. Have personal intercultural experience
Importance/

Achievement

Importance

Achievement

$\begin{array}{llll}51 & 4.18 & 1.76 & 1-7\end{array}$

$\begin{array}{llll}51 & 4.35 & 1.86 & 1-7\end{array}$

Importance $\quad \begin{array}{llll}62 & 2.31 & 1.72 & 1-6\end{array}$

$\begin{array}{lllll}\text { Achievement } \quad 57 & 2.96 & 1 / 74 & 1-6\end{array}$

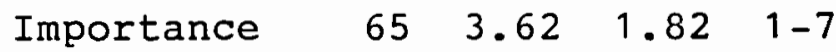

Achievement $\begin{array}{llll}64 & 3.98 & 2.00 & 1-7\end{array}$

Importance $\quad \begin{array}{llll}65 & 3.78 & 2.40 & 1-7\end{array}$

Achievement $\begin{array}{llll}63 & 3.54 & 2.23 & 1-7\end{array}$

Importance $\quad \begin{array}{llll}63 & 5.00 & 1.88 & 1-7\end{array}$

Achievement $\begin{array}{llll}63 & 5.00 & 1.68 & 1-7\end{array}$ 